Research Article

\title{
Test and Numerical Analysis on Damaged Steel Beam Strengthened with Prestressed CFRP Sheet
}

\author{
Wenyu Hou $\mathbb{D}^{1},{ }^{1}$ Fengchi Wang, ${ }^{1}$ and Lianguang Wang ${ }^{2}$ \\ ${ }^{1}$ School of Transportation Engineering, Shenyang Jianzhu University, Shenyang 110168, China \\ ${ }^{2}$ School of Resources and Civil Engineering, Northeastern University, Shenyang 110819, China \\ Correspondence should be addressed to Wenyu Hou; houwenyu61@163.com
}

Received 30 April 2021; Revised 26 August 2021; Accepted 30 August 2021; Published 8 September 2021

Academic Editor: Piotr Smarzewski

Copyright (c) 2021 Wenyu Hou et al. This is an open access article distributed under the Creative Commons Attribution License, which permits unrestricted use, distribution, and reproduction in any medium, provided the original work is properly cited.

This paper presents the experimental and numerical analysis of damaged steel beams strengthened with prestressed CFRP sheet or only strengthened with CFRP sheet. The test results showed that damaged level had a significant effect on the stiffness, yield load, and ultimate bearing capacity. And using prestressing CFRP sheet to strengthen damaged steel beam could increase the ultimate bearing capacity. The numerical analysis results showed that the damaged level had a significant effect on the stiffness and ultimate bearing capacity. The strengthened steel beam with the damaged level could exceed the steel beam without damage by about $10 \%$ in the ultimate bearing capacity. The ultimate bearing capacity would increase about $8 \%$ when the flange or web thickness increased per $1 \mathrm{~mm}$. The ultimate bearing capacity would increase about $3 \%$ when the thickness or width of CFRP sheet increased per $0.05 \mathrm{~mm}$ or $10 \mathrm{~mm}$. The bearing capacity would increase about $1.5 \%$ when the prestressed degree increased about $7 \%$.

\section{Introduction}

Steel structure may be damaged by the erosion of natural environment, natural disasters, improper operation, loading, and human factors when the structure had been serviced over a long period of time [1]. And the damage will reduce the bearing capacity and durability and even lead to structure failure. In order to prolong the service life and ensure the security of the damaged steel structure, it is necessary to replace or reinforce the damaged structure [2]. But replacement of damaged members would waste a lot of financial and material resources. At the same time, the way of replacement may affect the use of the other parts of the structure. At present, the repair work of the engineering structures had become a necessary and regular work, which required a large amount of investment every year. Therefore, it is an urgent task to find an economical and efficient method for repairing the steel structure.

In recent years, a new method of repair damaged steel structures using CFRP (Carbon Fiber Polymer) sheets has been proposed. CFRP sheets have the material and mechanical properties such as low self-weight, high strength, and durability. And the CFRP sheet can be epoxy-bonded to the damaged members to restore the bearing capacity and durability. During the past years, there have been many studies on repairing the steel members with FRP materials. Kim and Harries [3] tested the static and fatigue properties of 6 repaired beams, focusing on the local plasticity and the CFRP-steel interface. Three-dimensional finite element analysis (FEA) was used to predict the experimental behavior. CFRP restored the static carrying capacity of the damaged beam to the level of the undamaged beam. The stress range at the damage area affected the fatigue life, damage propagation, and plastic strain development of the repaired beams. The fatigue crack propagation on the web of beam was not significant over $50 \%$ of the fatigue life, while the brittle web fracture exceeded the threshold value. A bilinear fatigue response was observed at the interface between CFRP and steel, and the strength depended on the number of fatigue cycles and the range of applied stress. $\mathrm{Wu}$ et al. [4] studied the fatigue properties of artificially notched steel beams strengthened by 4 different materials under equivalent tensile stiffness. The test results showed that the application of fiber reinforced composite plate could not 
only delay the crack initiation, reduce the crack growth rate, and prolong the fatigue life, but also reduce the stiffness decay and residual deflection. Yu et al. [5] studied the effectiveness of CFRP plates in prolonging the fatigue life of steel structures. The experimental results showed that the CFRP patches could effectively slow down the crack propagation and prolong the fatigue life and the later strengthening tends to prolong the residual fatigue life more significantly under the larger damage level. Bocciarelli and Colombi [6] proposed a simple method for calculating the elastoplastic response of steel beams strengthened with CFRP. The main conclusion was that the reinforced section must achieve a large curvature in order to develop its ultimate bending moment resistance, so it was necessary to use stiffeners to avoid local instability problems in the webs and in the flanges. Hmidan et al. [7] studied the crack-tip properties of $W 4 \times 13$ steel beams with wide flanges reinforced with CFRP sheets. The results showed that the number of layers and modulus of CFRP affected the cracktip plasticity of the strengthened beams. Colombi et al. [8] conducted the fatigue tests on cracked steel plates (a single edge specimen) reinforcing by strips bonded to a single side. The results showed that CFRP materials bonded around the tip area prolonged the fatigue life of the damaged steel elements about 3 times. Ghafoori and Motavalli [9] conducted experimental and numerical studies on lateral-torsional buckling (LTB) of steel beams strengthened by CFRP laminates with normal modulus (NM). It showed that increasing the prestress in CFRP laminates did not always increase the buckling strength of the reinforced slender steel beams. Wang et al. [10] used CFRP and prestressed CFRP sheets to repair steel-concrete composite beams. The results showed that the yield load of reinforced composite beams was not significantly affected by CFRP sheets, but the ultimate load was significantly affected by CFRP sheets. Colombi and Fava [11] performed fatigue loading on 9 CFRP reinforced fractured steel beams. Experimental results revealed that there was a debonding area between the reinforcement and the steel substrate at the crack location. Debonding obviously had adverse effect on the reinforcement effectiveness. Gholami et al. [12] evaluated the performance of I-section steel beams strengthened with pultruded CFRP plate on the bottom flange after exposure to diverse conditions (including natural tropical climate, wet/ dry circulation, plain water, salt water, and acidic solution). It was found that the bonding layer was the critical part of the system which was directly related to the system performance, and the ductility of all strengthened beams increased after exposure. Aljabar et al. [13] extended the existing knowledge of CFRP strengthening of steel elements under tensile fatigue loading to the case of mixed tension and shear loads. In order to describe the effect of mixing mode on the crack propagation, a shifting phenomenon was found. A mixed mode modification factor was developed to estimate the fatigue life of CFRP-strengthened steel plates with inclined initial cracks. Hu et al. [14] proposed fatigue design guides and programs for CFRP-strengthened steel structures. The results showed that CFRP was effective in strengthening steel structures under fatigue. CFRP could extend the fatigue life under a certain loading condition or increase the allowable stress range when a certain fatigue life was required. Yousefi et al. [15] presented the experimental and numerical results of failure analysis and structural behavior of notched steel I-beams reinforced by bonded CFRP plates under static load. The results showed that the CFRP failure modes in strengthening of deficient steel I-beams included end-debonding, below point load debonding, splitting, and delamination. Jankowiak and Madaj [16] used the passive method to calculate the composite beam strengthened with prestressing CFRP strips by ABAQUS. The results showed that different initial strain values had little effect on the improvement of ultimate bearing capacity and stiffness of composite beams. Using CFRP strips to strengthen the composite beams could reduce the number and width of cracks and could significantly improve the durability of the structure. Omar et al. [17] used test and finite element to analyze 178 models, covering 6 variables representing common problem parameters: the slenderness ratio of web, the monosymmetric ratio of I-beam, the area of CFRP, the modulus of elasticity of CFRP, the tensile strength of CFRP, and the length of CFRP sheet. The parametric study showed that CFRP sheets were very efficient in reinforcing compact monosymmetric sections, whereas the enhancement in beams with noncompact sections was very small. CFRP sheets were able to reach its ultimate strength as enough bond length was ensured. Analytical procedure for calculating the flexural strength of steel I-shaped beams reinforced with CFRP sheets at tension flange was presented. Bocciarelli et al. [18] proposed analytical and numerical models of elastobrittle adhesives to evaluate the stress and strain distribution in the reinforcement at a given crack length. The results of experimental were considered to validate the proposed numerical and analytical techniques. The calculated results were in good agreement with the experimental results, with the accuracy of the proposed models. Martinelli et al. [19] studied the bonding behavior of fiber reinforced polymer (FRP) composites glued to steel substrate by experimental and numerical simulation. The results showed that the incorporated bond-slip relationship in the proposed numerical model had a significant effect on the numerical results. Therefore, it was important to identify the realistic bond-slip relationships under different adhesive types and curing conditions (by conducting experimental tests). The performed parametric study had implied that using FRP composites with higher elastic modulus or application of thicker FRP reinforcement results in an increased prestress release/lap-shear capacity of the FRP-to-steel bonded joints, provided that there was enough bond length. Li et al. [20] tested 8 notched steel beams strengthened with a CFRP plate under four-point bending after suffering from overloading fatigue and/or 400 wetting/drying cycles (WDCs) with $3.5 \mathrm{wt} \% \mathrm{NaCl}$ solution. The experimental results showed that overloading fatigue and/or WDCs significantly affected the mechanical properties of retrofitted steel beams. The strength and stiffness of the overloaded damaged beams were continuously degraded by WDCs, whereas the beams without overloading damage only suffered from the first 90 WDCs. As observed from the 
strain distribution and debonding failure modes, the WDCs initiated debonding along the steel beam/adhesive interface and degraded the adhesive bonding over all the bonding surfaces. Meanwhile, overloading damage mainly occurred near the notch and resulted in bond degradation of the CFRP plate/adhesive interface, which induced salt solution penetration and thus further degraded the adhesive bonding.

In this paper, the tension flange was partly sawn at midspan to simulate the damage of steel beams. And CFRP sheets or prestressed CFRP sheets were bonded to the lower side of the flange of steel beams to restore the bearing capacities and the elastic stiffness in the test. Because the test cannot consider all the parameters, finite element softwareABAQUS was used to analyze the variation of load, deflection, and stress along the length of steel beam under different parameters.

\section{Experimental Program}

A total of four damaged steel beams were fabricated. The steel beams were made of typical Chinese Standard steel I14A of which the depth was $140 \mathrm{~mm}$, the width of flange was $80 \mathrm{~mm}$, the thicknesses of flange and web were $9.1 \mathrm{~mm}$ and $5.5 \mathrm{~mm}$, respectively, and the area of section was $2,150 \mathrm{~mm}^{2}$. The steel sections were cut into $1.6 \mathrm{~m}$ long beams and two different damaged levels of $50 \%$ and $100 \%$ loss of tension flange were cut at midspan of the steel beams, as shown in Figure 1(b). Tensile test of I-shaped steel was conducted. The yield strength and tensile strength of I-shaped steel were $256 \mathrm{MPa}$ and $423 \mathrm{MPa}$, respectively. The externally bonded strengthening systems selected for this study were highstrength CFRP sheets. The thickness of the CFRP sheets was $0.167 \mathrm{~mm}$, the wide was $50 \mathrm{~mm}$, and the length was $1,300 \mathrm{~mm}$. Tensile test of CFRP sheets was conducted, and an average tensile strength was $3,456 \mathrm{MPa}$; elastic modulus was $258 \mathrm{GPa}$. The resin adhesive used to paste CFRP sheet was matched with CFRP sheet, and its shear strength was 19.4 MPa. Two different attachment patterns were, namely, CFRP sheet and prestressed CFRP sheet. The prestress was applied to the CFRP sheets by using self-made stretching bed. Implementation method: fixed CFRP sheets by two steel slabs with four bolts at the end of stretching bed and four screws which could move up and down; applied prestress to the CFRP sheets by raising the supports horizontally, as shown in Figure 2. Prestressed CFRP sheets or CFRP sheets were pasted on the bottom of the tension flange and then pasted the U-shape hoops at the end of CFRP sheets to make sure the CFRP sheets could be anchored to the steel beams. The detailed parameters of the steel beams are given in Table 1 . The steel beams were loaded in four-point bending with $500 \mathrm{~mm}$ spacing between two concentrated point loads and with two equal shear spans of $500 \mathrm{~mm}$. Rubber bearings were used at the supports. Loading was applied across the full width of the top flange of steel beam by spreader beam that were placed between the rubber bearings on the top of the steel beam. Four-point bending tests were performed using hydraulic jacks, as shown in Figure 3. Monotone grading loading was adopted in this test. And the load of each stage was $2 \mathrm{kN}$. When the specimen was close to failure, slow and continuous loading was used until the specimen was destroyed.

\section{Test Results}

3.1. Failure Mode. The steel beams repaired with adhesively bonded prestressed CFRP sheet or CFRP sheet could display four distinct failure modes including the top flange buckling; some part of CFRP sheet debonding; CFRP sheet ruptured with the top flange buckling; CFRP sheet rupture.

Because of no CFRP sheet bonded, the failure of SB0 was the top flange buckling. The CFRP sheet ruptured with the top flange buckling happened in the CFSB2 and because of the prestressed CFRP sheet bonded, the failure mode of CFSB1 was some part of CFRP sheet debonding and some part rupture. The CFSB3's failure mode was some part of CFRP sheet debonding and the bottom flange crippling because of the damaged level of CFSB3 was larger than others. The failure modes are shown in Figure 4.

3.2. Effect of Prestressed CFRP Sheet. Figure 5(a) shows the load versus midspan deflection of the steel beams SB0 and CFSB1. CFSB1 was strengthened with prestressed CFRP sheet and SB0 was not strengthened. The yield load of CFSB1 was $18.1 \%$ greater than that of SB0, and the stiffness was $28.8 \%$ greater than that of SB0. The ultimate load of CFSB1 was $17.1 \%$ greater than that of SB0. The results showed that epoxy-bonded prestressed CFRP sheet had significantly increased the yield load, ultimate bearing capacity, and the stiffness of the damaged steel beam.

3.3. Effect of Damaged Level. Figure 5(b) shows the load versus midspan deflection of the steel beams CFSB1 and CFSB3. CFSB1 was the strengthened steel beam with the $50 \%$ damaged level and CFSB3 was the strengthened steel beam with $100 \%$ damaged level. The yield load and ultimate load of CFSB1 were, respectively, $57.6 \%$ and $58.7 \%$ greater than those of CFSB3, and the stiffness was $55.6 \%$ greater than that of CFSB3. It showed that the stiffness, yield load, and ultimate load could reduce about $50 \%$ when the damaged level was double.

3.4. Effect of Prestressing. Figure 5(c) shows the load versus midspan deflection of the steel beams CFSB1 and CFSB2. CFSB1 was the strengthened steel beam with prestressed CFRP sheet and CFSB2 was the strengthened steel beam with CFRP sheet. The stiffness of CFSB1 was $16.1 \%$ greater than that of CFSB2. The yield load and ultimate load were, respectively, $7 \%$ and $1 \%$ greater than those of CFSB2. It showed that the prestressing had a significant effect on the stiffness but had little effect on the yield load and ultimate load. 


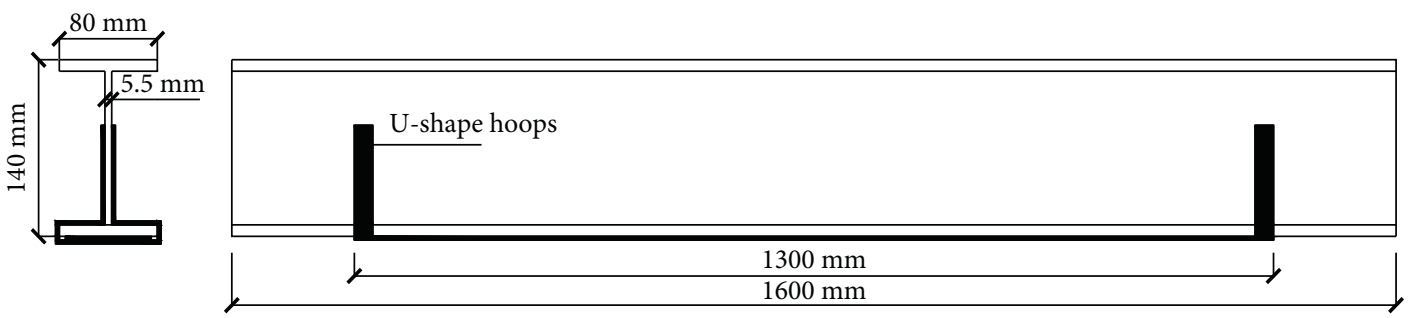

(a)
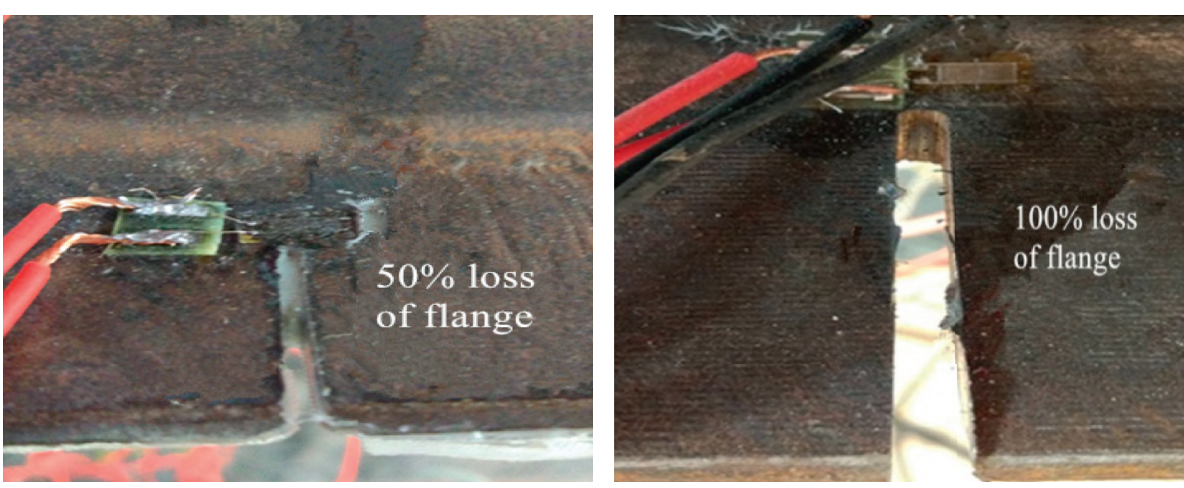

(b)

Figure 1: The preparation of specimens. (a) Dimension and strengthened method. (b) Damaged model.

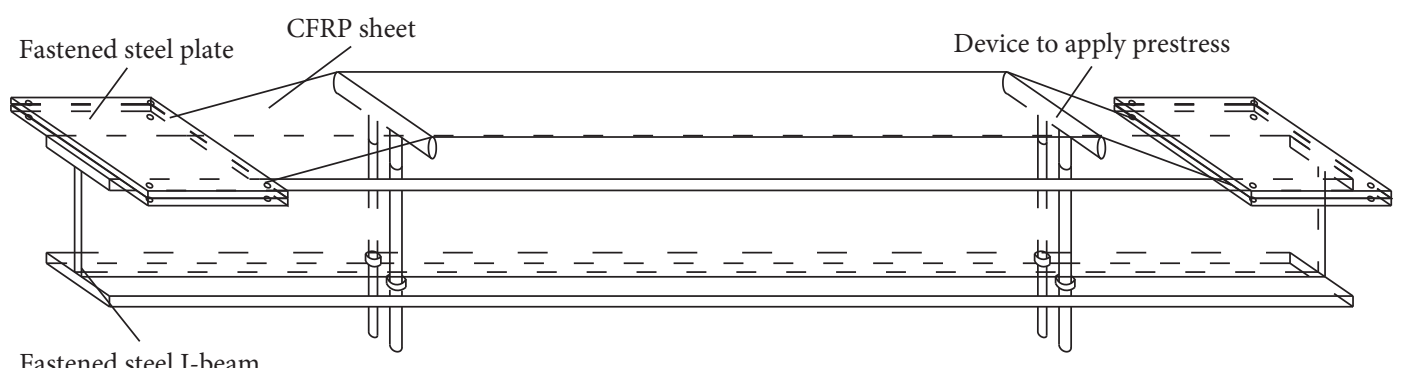

Fastened steel I-beam

FIGURE 2: Device for applying prestress to CFRP sheet.

TABLE 1: Test matrix and results.

\begin{tabular}{|c|c|c|c|c|c|c|c|}
\hline $\begin{array}{l}\text { Specimen } \\
\text { number }\end{array}$ & $\begin{array}{c}\text { Prestressed } \\
\text { degree }(\% P u)\end{array}$ & $\begin{array}{l}\text { Damaged } \\
\text { level (\%) }\end{array}$ & Type of CFRP & $\begin{array}{c}\text { Yield load of } \\
\text { bottom flange } P_{t} \\
(\mathrm{kN}) /\left(\% P_{u}\right)\end{array}$ & $\begin{array}{c}\text { Yield load of top } \\
\text { flange } P y(\mathrm{kN}) / \\
(\% P u)\end{array}$ & $\begin{array}{l}\text { Ultimate load } \\
\qquad P u(\mathrm{kN})\end{array}$ & $\begin{array}{c}\text { Failure modes } \\
\text { (CFRP sheet) }\end{array}$ \\
\hline SB0 & 0 & 50 & $\begin{array}{c}\text { Not } \\
\text { strengthened }\end{array}$ & $41 /(30)$ & $95 /(69.5)$ & 136.6 & - \\
\hline CFSB1 & 13 & 50 & $\begin{array}{l}\text { Prestressed } \\
\text { CFRP sheet }\end{array}$ & $53.1 /(33.2)$ & $112.2 /(70.1)$ & 160 & $\begin{array}{l}\text { Some part } \\
\text { debonding and } \\
\text { rupture }\end{array}$ \\
\hline CFSB2 & 0 & 50 & CFRP sheet & $53.9 /(34.1)$ & $104.5 /(66.1)$ & 158.2 & Rupture \\
\hline CFSB3 & 13 & 100 & $\begin{array}{l}\text { Prestressed } \\
\text { CFRP sheet }\end{array}$ & $36.2 /(35.8)$ & $71.2 /(70.6)$ & 100.8 & $\begin{array}{l}\text { Some part } \\
\text { debonding }\end{array}$ \\
\hline
\end{tabular}




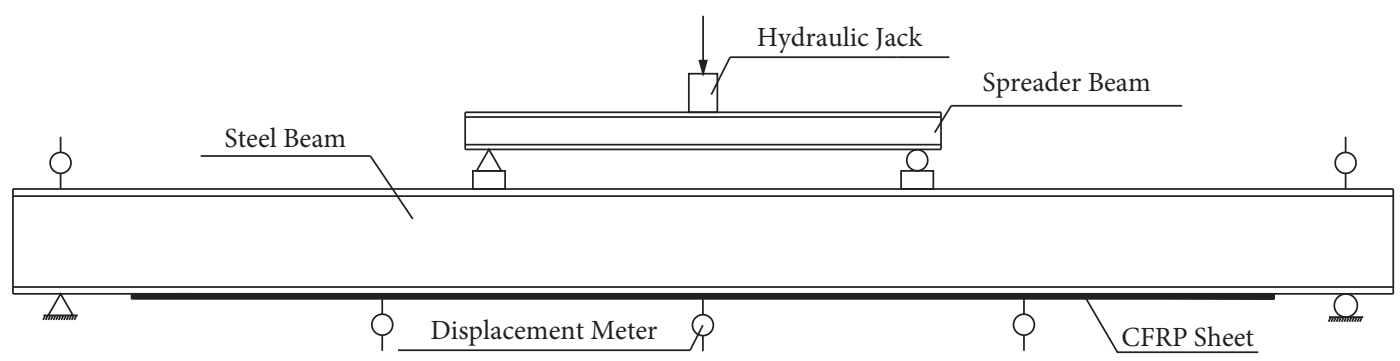

FIgURe 3: Loading device of test.

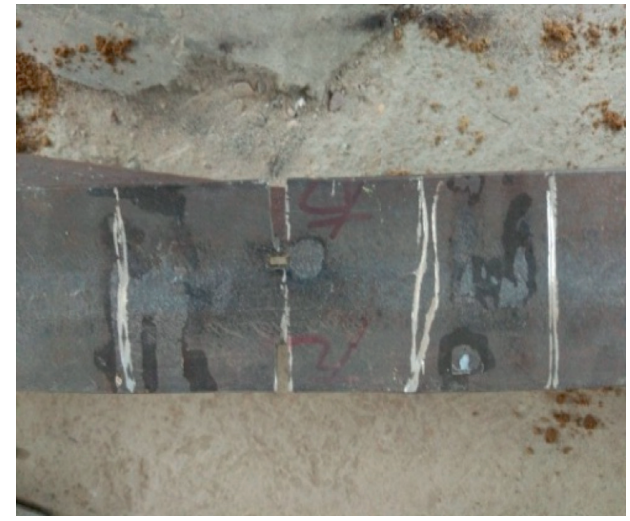

(a)

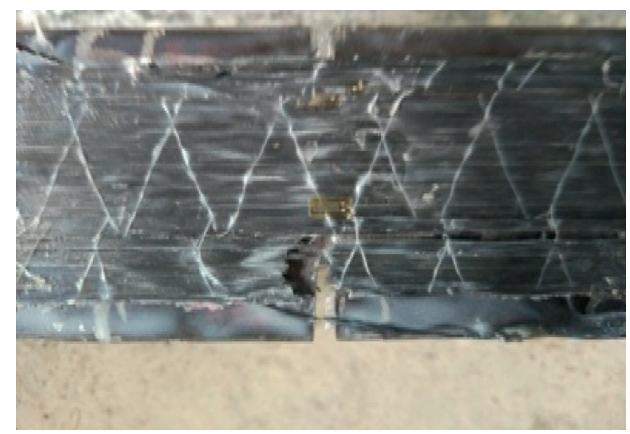

(c)

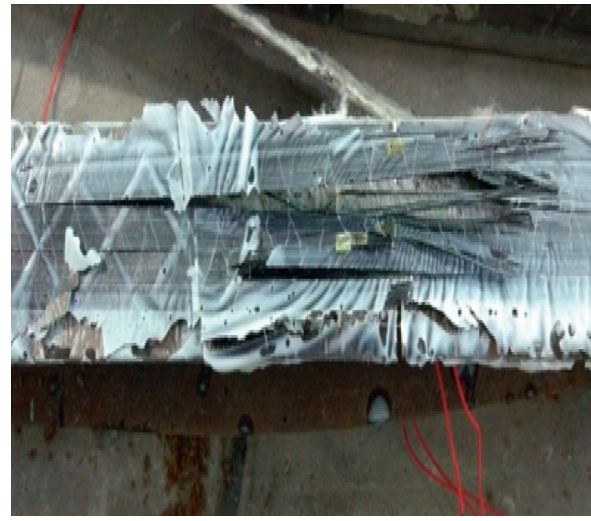

(b)

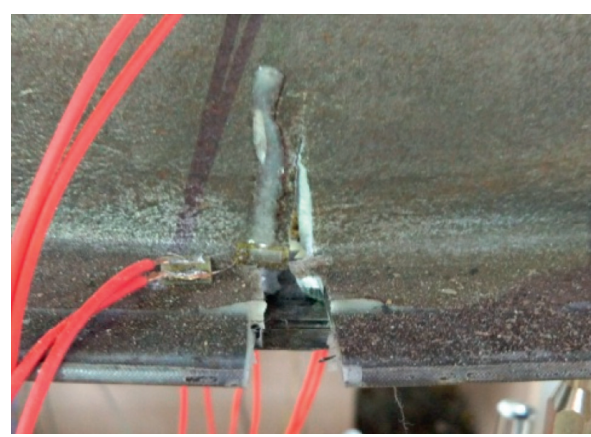

(d)

Figure 4: Failure modes of test specimens. (a) SB0. (b) CFSB1. (c) CFSB2. (d) CFSB3.

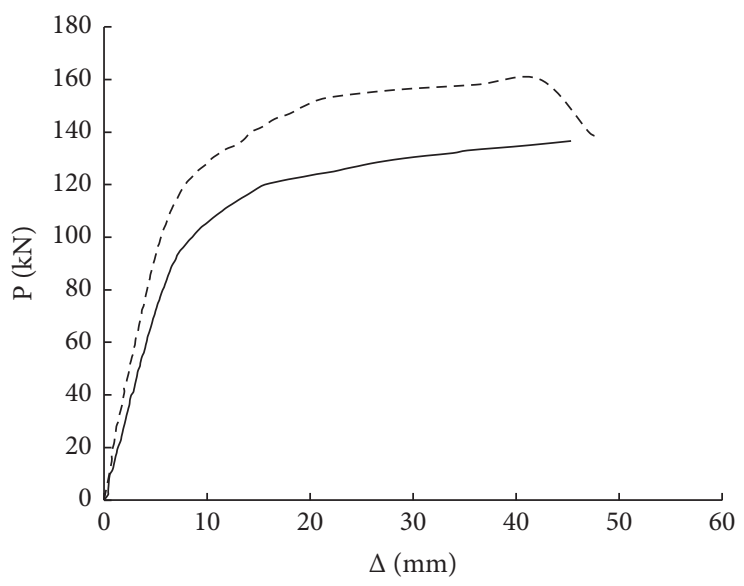

- SB0

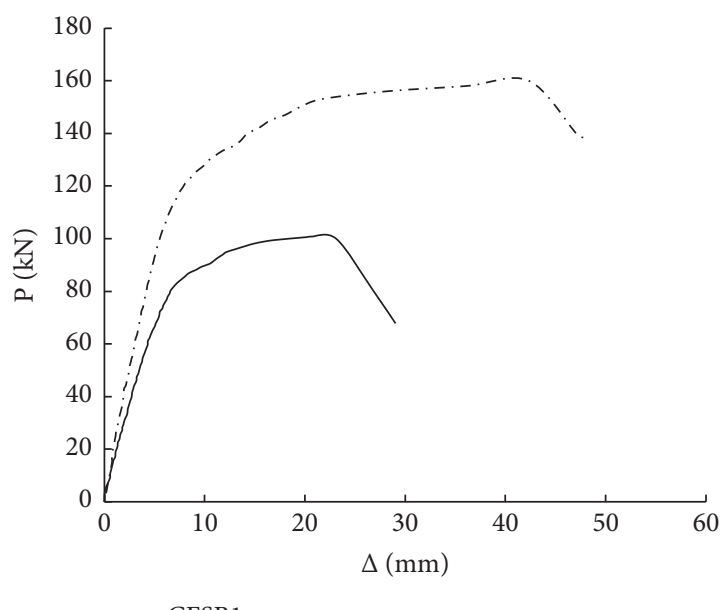

$\cdot-\cdot$ CFSB1

(a) 


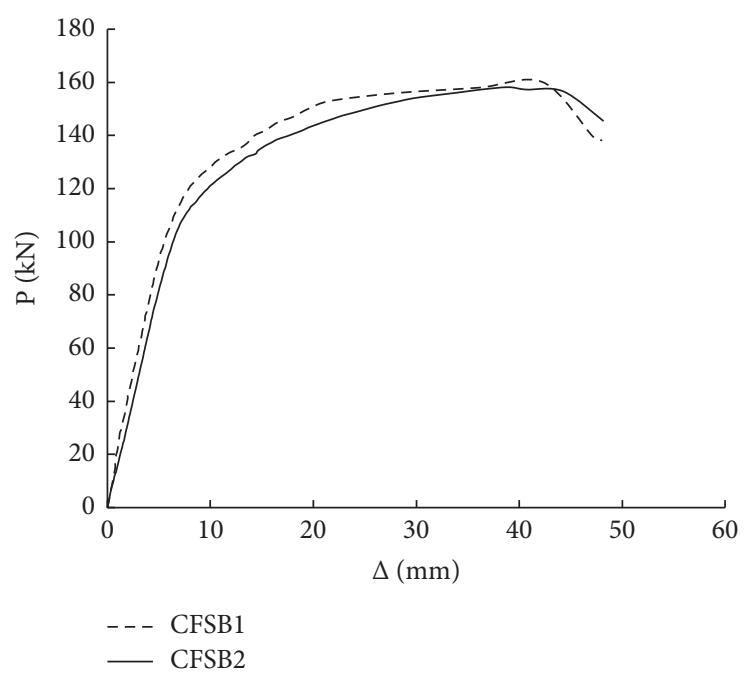

(c)

FIGURE 5: Relationship between load and deflection of steel beam. (a) Effect of prestressed CFRP sheet. (b) Effect of damaged level. (c) Effect of prestressing.

\section{Numerical Analysis}

\subsection{Material Properties}

4.1.1. Steel Beam. The steel beam was assumed to be an elastic-plastic material identical in tension and compression as shown in Figure 6 and the relationship of stress and strain was

$$
\sigma= \begin{cases}E_{\mathrm{t}} \varepsilon_{\mathrm{t}}, & \left(\varepsilon_{\mathrm{t}} \leq \varepsilon_{\mathrm{te}}\right), \\ -A \varepsilon_{t}^{2}+B \varepsilon_{t}+C, & \left(\varepsilon_{\mathrm{te}}<\varepsilon_{t} \leq \varepsilon_{\mathrm{te} 1}\right), \\ f_{\mathrm{ty}}, & \left(\varepsilon_{\mathrm{te} 1}<\varepsilon_{t} \leq \varepsilon_{\mathrm{te} 2}\right), \\ f_{\mathrm{ty}}\left[1+0.6 \frac{\varepsilon_{\mathrm{t}}-\varepsilon_{\mathrm{e} 2}}{\varepsilon_{\mathrm{e} 3}-\varepsilon_{\mathrm{e} 2}}\right], & \left(\varepsilon_{\mathrm{te} 2}<\varepsilon_{\mathrm{t}} \leq \varepsilon_{\mathrm{te} 3}\right), \\ 1.6 f_{\mathrm{ty}}, & \left(\varepsilon_{\mathrm{t}}>\varepsilon_{\mathrm{te} 3}\right),\end{cases}
$$

where $\quad A=0.2 f_{\mathrm{ty}} /\left(\varepsilon_{\mathrm{te} 1}-\varepsilon\right)^{2}, \quad B=2 A \varepsilon_{\mathrm{tel}}, \quad C=0.8 f_{\mathrm{ty}}+$ $A\left(\varepsilon_{\mathrm{te}}\right)^{2}-B \varepsilon_{\mathrm{te}}, \quad \varepsilon_{\mathrm{te}}=0.8 f_{\mathrm{ty}} / E_{\mathrm{t}}, \quad \varepsilon_{\mathrm{te} 1}=1.5 \varepsilon_{\mathrm{te}}, \quad \varepsilon_{\mathrm{te} 2}=10 \varepsilon_{\mathrm{te}}$, $\varepsilon_{\mathrm{te} 3}=100 \varepsilon_{\mathrm{te}}, E_{\mathrm{t}}$ was the elastic modulus of steel, $f_{\mathrm{ty}}$ was the yield strength of steel, and $f_{\text {tu }}$ was the ultimate strength of steel.

4.1.2. CFRP Sheet. The CFRP sheet was assumed to be an orthotropic material as shown in Figure 7 and the relationship of stress and strain was

$$
\begin{cases}\sigma_{c f}=E_{c f} \varepsilon_{c f}, & 0 \leq \varepsilon_{c f} \leq \varepsilon_{c f u}, \\ \sigma_{c f}=0, & \varepsilon_{c f u} \leq \varepsilon_{c f},\end{cases}
$$

where $\varepsilon_{c f}$ was the strain of CFRP sheet, $\sigma_{c f}$ was the stress of CFRP sheet, $\varepsilon_{c f u}$ was the allowable ultimate strain of CFRP sheet, and $E_{c f}$ was the elastic modulus of CFRP sheet.

4.2. Model Development. The numerical analysis was performed using the software ABAQUS. Geometry and loading arrangements of the model were adopted in accordance with the experimentally tested beams. A three-dimensional element (C3D8R) was created for steel beam and shell-type element (SR4) for CFRP sheet as shown in Figure 8.

4.3. Prestressing. Falling temperature method was used in ABAQUS to prestress in the CFRP sheet and the relationship of temperature and load was

$$
T=-\frac{P}{\alpha_{f} E_{f} A_{f}},
$$

where $T$ was the temperature, $\alpha_{f}$ was the coefficient of linear expansion of CFRP sheet, $E_{f}$ was the elastic modulus of CFRP sheet, $A_{f}$ was the sectional area of CFRP sheet, and $P$ was the load as the temperature falling.

4.4. Stress Analysis. Figure 9 shows the load and deflection curve of damaged steel beam strengthened with CFRP sheet. The load-deflection curve was nonlinear and it included three phases: elastic phase, elastic-plastic phase, and plastic phase. When the strengthened steel beam was in the elastic phase, the deflection increased slowly as the load increased. When the strengthened steel beam was in the elastic-plastic phase, the deflection increased quickly as the load increased. When the strengthened steel beam was in the plastic phase, the deflection increased quickly but the load increased a little. 


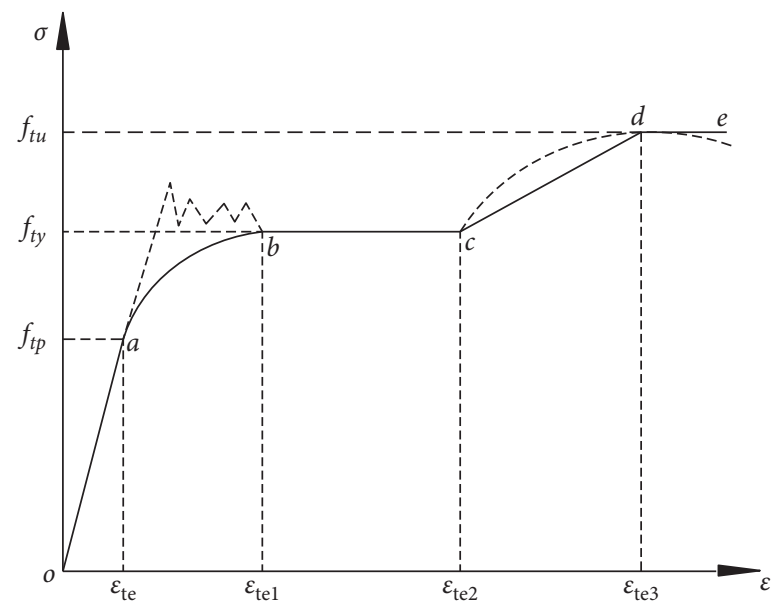

Figure 6: Stress-strain relationship of steel.

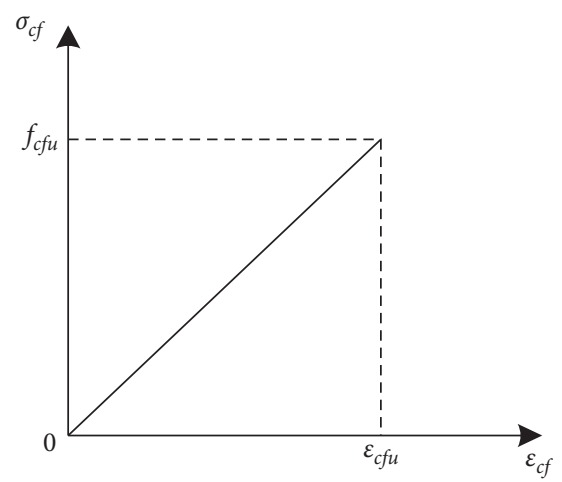

FIgURE 7: Stress-strain relationship of CFRP sheet.

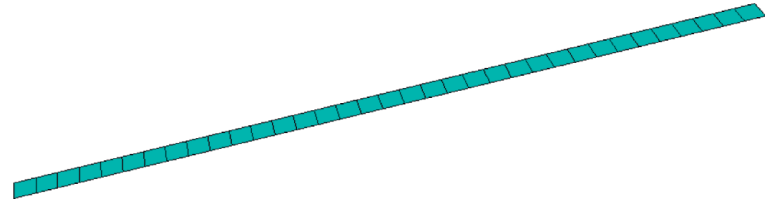

(a)

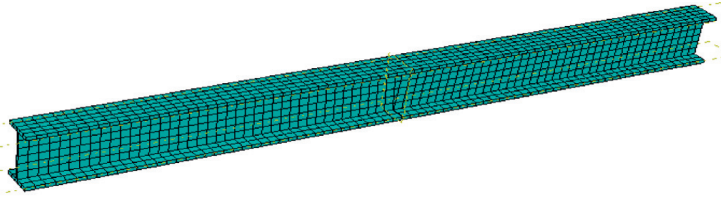

(b)

Figure 8: Model development. (a) CFRP sheet. (b) Steel beam.

Figure 10 shows the stress images of steel beam and CFRP sheet. When the load reached about $33 \% \mathrm{Pu}(\mathrm{Pu}$ was the ultimate load), the bottom flange of steel beam was yielded. But because of the CFRP sheet, the yielded area was restricted. When the load reached about $66 \% \mathrm{Pu}$, the top flange of steel beam was yielded. The yielded area developed quickly. When the load reached the ultimate load, the strengthened steel beam was failed.

Figure 11 shows the relationship of stress along steel beam length, stress along steel beam width, and stress along CFRP sheet's length. In the direction of steel beam length, the maximal stress appeared in the midspan and loading point. In the point $\mathrm{A}$, the maximal tensile stress appeared in the midspan and the pressure stress was almost same in the midspan and loading point. In the point $\mathrm{B}$, the stress in the loading reached maximum and the stress in the midspan was almost the same in the points B and C. In the direction of steel beam width, the maximal tensile stress appeared in the centre of midspan and the pressure stress was almost the same everywhere in the point $\mathrm{A}$. The pressure stress was maximal in the centre of loading point and the tensile was almost the same everywhere in the point $\mathrm{A}$. In the point $\mathrm{B}$, the tensile stress of notch was almost same as the centre in the midspan. In the point $\mathrm{C}$, the maximal tensile stress appeared in the notch of midspan and the maximal tensile and pressure stress appeared in the centre of loading point. The pressure stress was almost the same in the centre of points B and C. The maximal stress of CFRP sheet always 


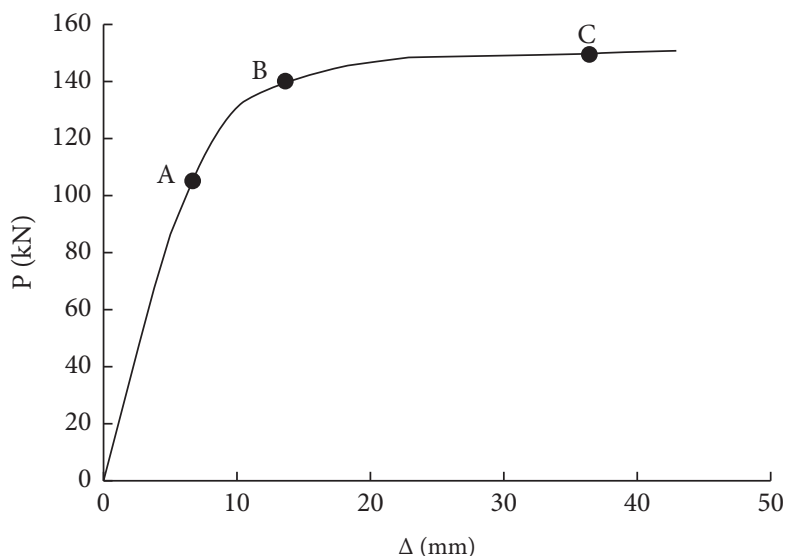

FIgURE 9: Load and deflection curve of damaged steel beam strengthened with CFRP sheet.
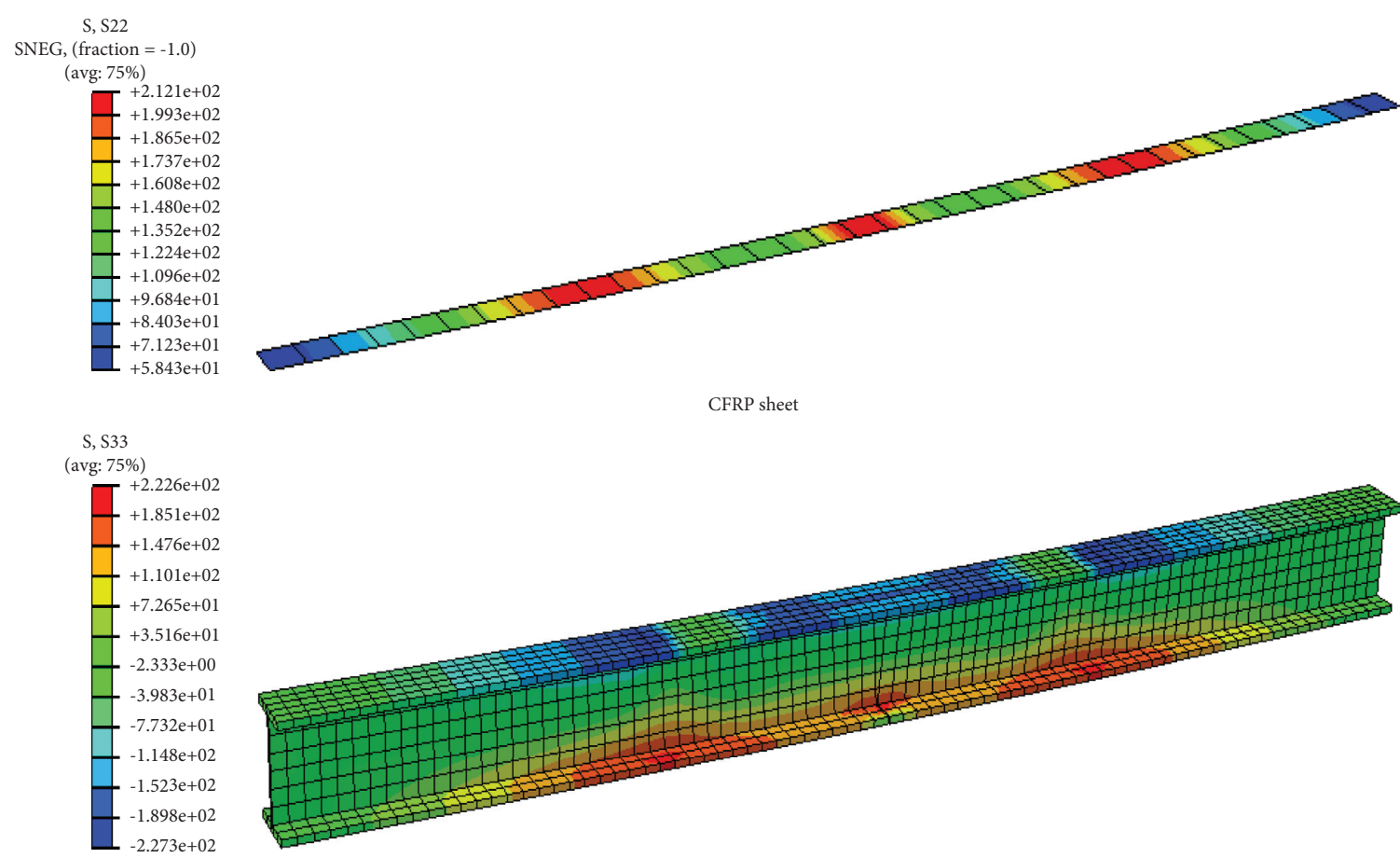

CFRP sheet

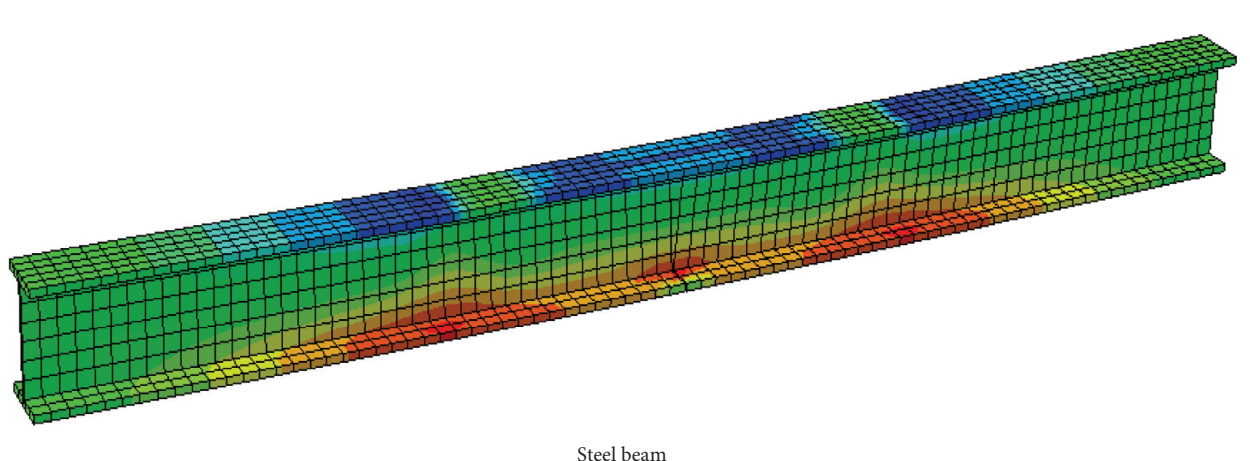

(a)

Figure 10: Continued. 


$$
\equiv
$$



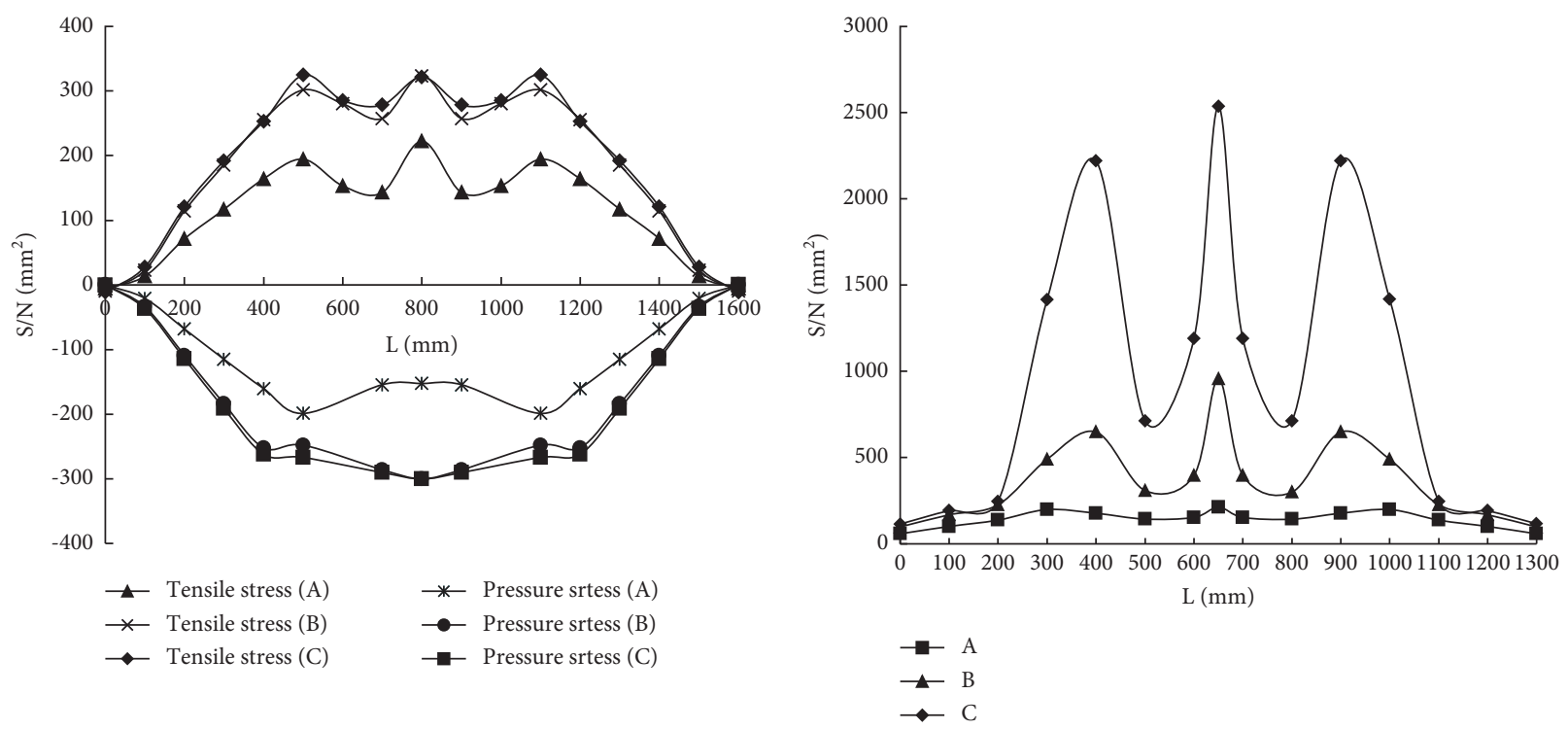

(a)

(b)

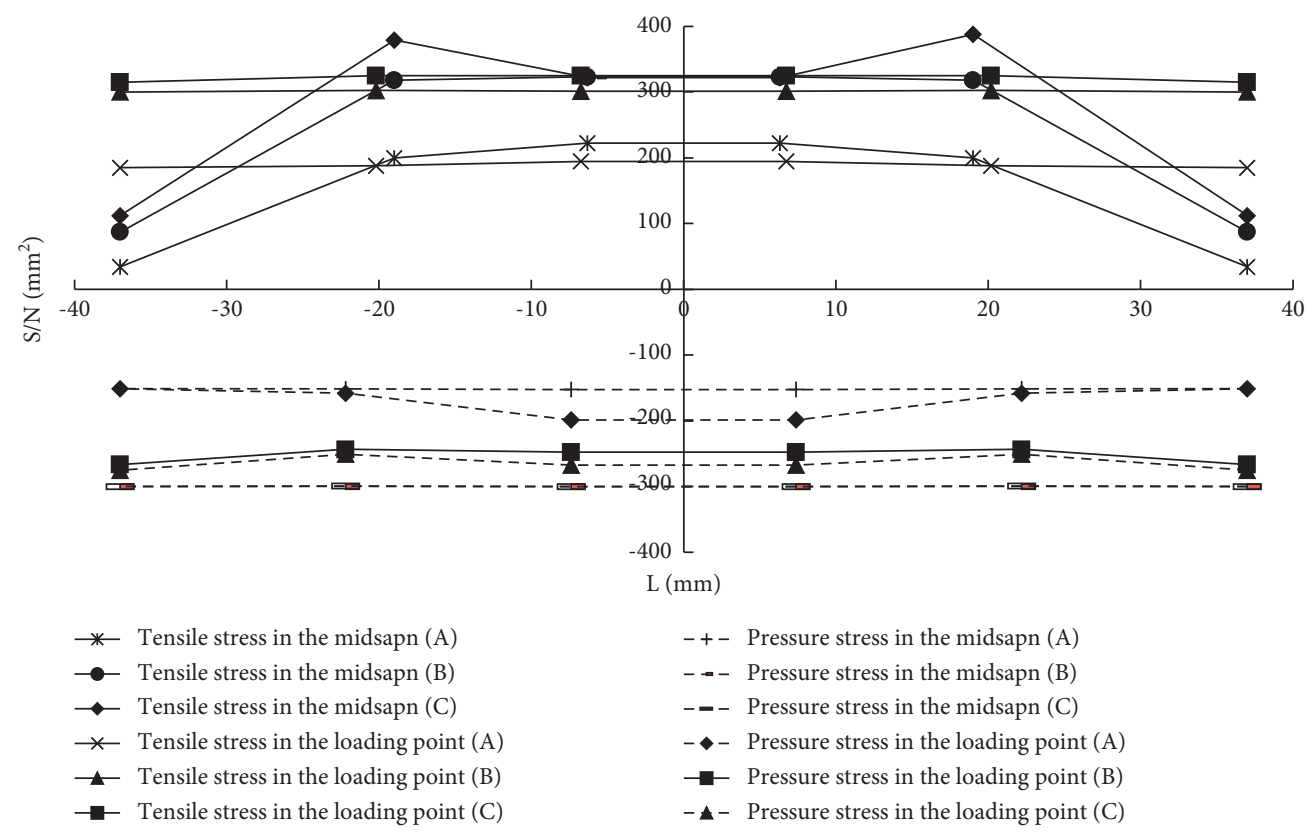

(c)

FIgURE 11: Stress curves. (a) Stress along steel beam length. (b) Stress along CFRP sheet's length. (c) Stress along steel beam width.

appeared in the midspan. In the point $A$, the stress of CFRP sheet was almost the same as the other place. But in the point $\mathrm{B}$, the stress of loading point was much bigger than the other place. In the point $\mathrm{C}$, the stress of loading point reached maximum, but it was still smaller the stress in the midspan.

4.5. Deflection Analysis. Figure 12 shows the deflection image of strengthened steel beam. When the bottom flange of steel beam became yielded, the deflection was about $3 \mathrm{~mm}$ and when the top flange of steel beam became yielded, the deflection was about $7 \mathrm{~mm}$. When strengthened steel beam failed (the bottom flange of steel beam was broken), the final deflection was $42.8 \mathrm{~mm}$.
4.6. The Comparison between Numerical Analysis Results and Test Results. Figure 13 shows the load-deflection comparison between numerical results and test results. Compared the numerical results and test results, agreement was also achieved no matter the steel beams were bare, strengthened with CFRP sheet, or strengthened with prestressed CFRP sheet.

\subsection{Parameter Analysis}

4.7.1. Damaged Level of Steel Beam. Figure 14 shows the load-deflection relationship of strengthened steel beam with different damaged level. The stiffness of strengthened steel beam with 10\%-90\% damaged level was, respectively, 


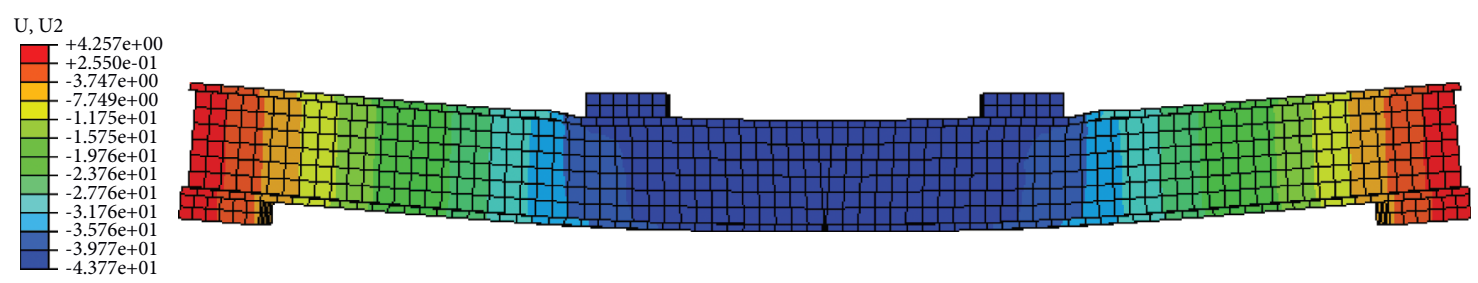

Figure 12: Deflection image.

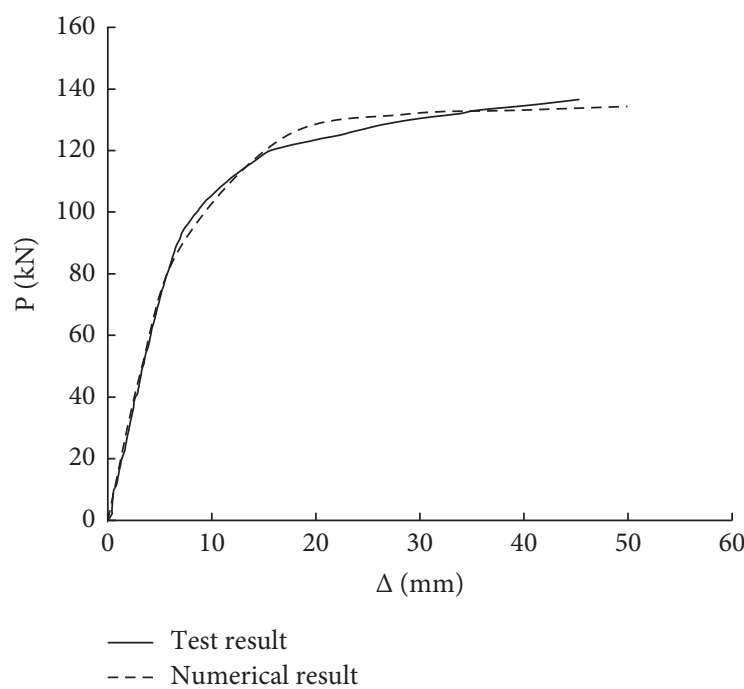

(a)

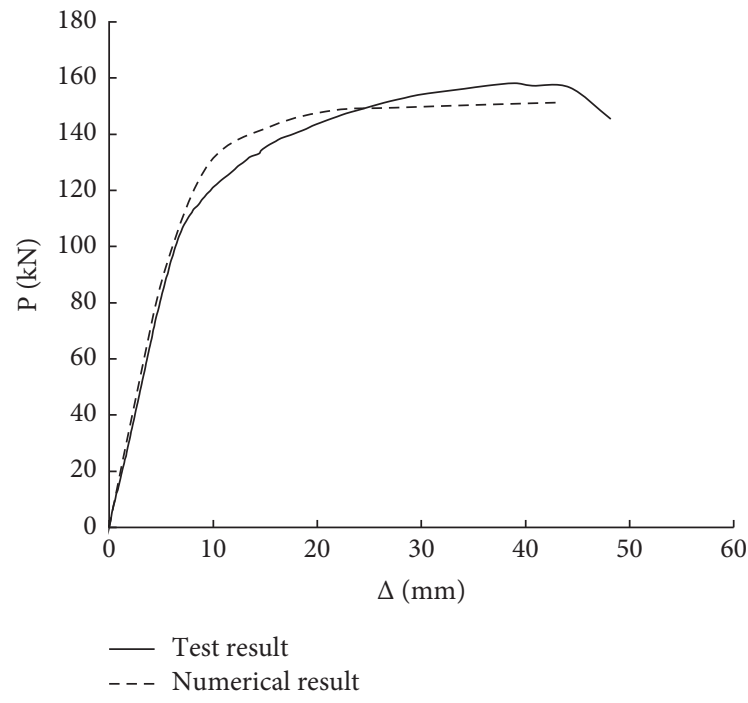

(c)

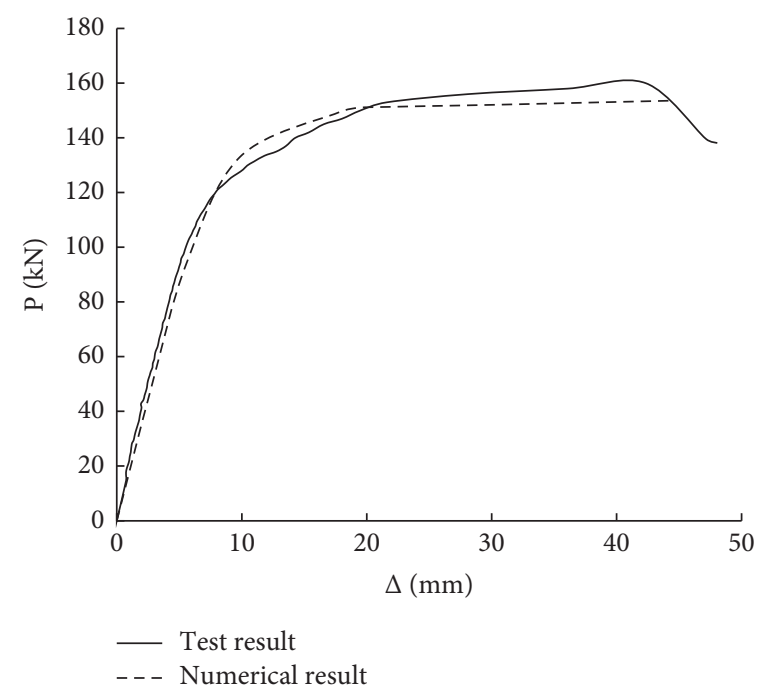

(b)

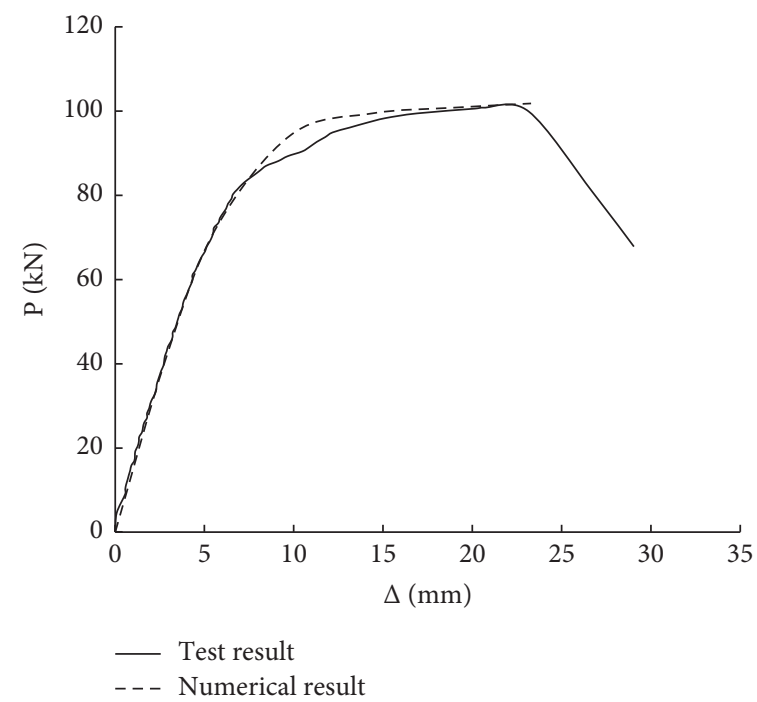

(d)

FIGURE 13: The comparison between numerical results and test results. (a) SB0. (b) CFSB1. (c) CFSB2. (d) CFSB3.

$49.1 \%, 47.1 \%, 44.5 \%, 41.7 \%, 37 \%, 34.3 \%, 36.5 \%, 23.7 \%$, and $16.2 \%$ greater than that of strengthened steel beam with $100 \%$ damaged level. And the ultimate load of strengthened steel beam with 10\%-90\% damaged level was, respectively, $82.8 \%, 75.8 \%, 68.4 \%, 60.3 \%, 48.1 \%$, $42.1 \%, 32.9 \%, 22.2 \%$, and $11.5 \%$ greater than that of strengthened steel beam with $100 \%$ damaged level. When the steel beam with $10 \%$ damaged level strengthened with $50 \mathrm{~mm}$ width CFRP sheet, the bearing capacity could exceed the steel beam without damage. The maximal tensile and pressure stress appeared in the midspan. When the damaged level was $10 \%-70 \%$, the tensile and pressure stress were almost the same. When the damaged level was bigger than $80 \%$, the tensile and pressure stress in the 


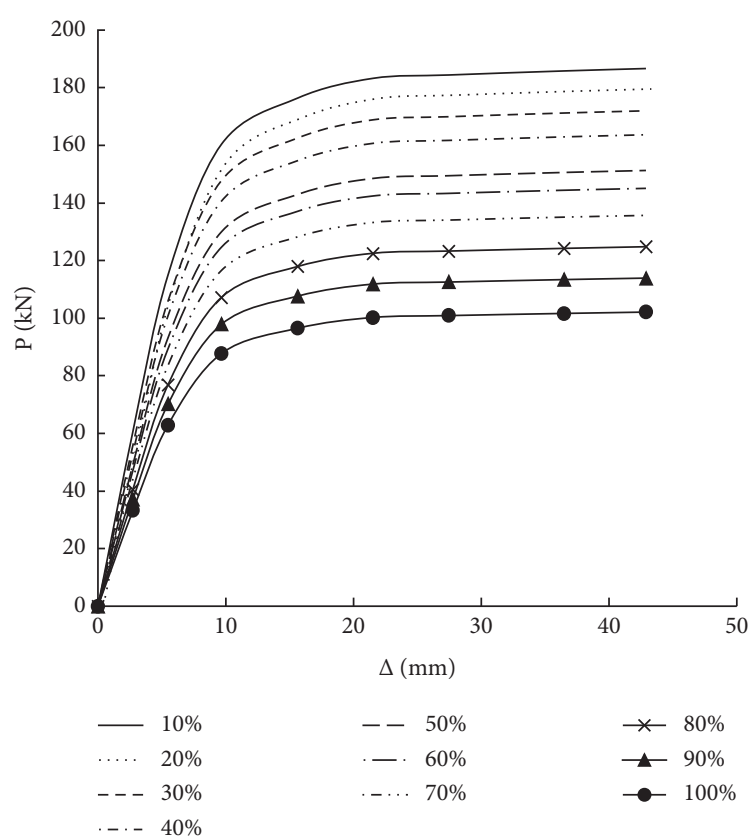

(a)

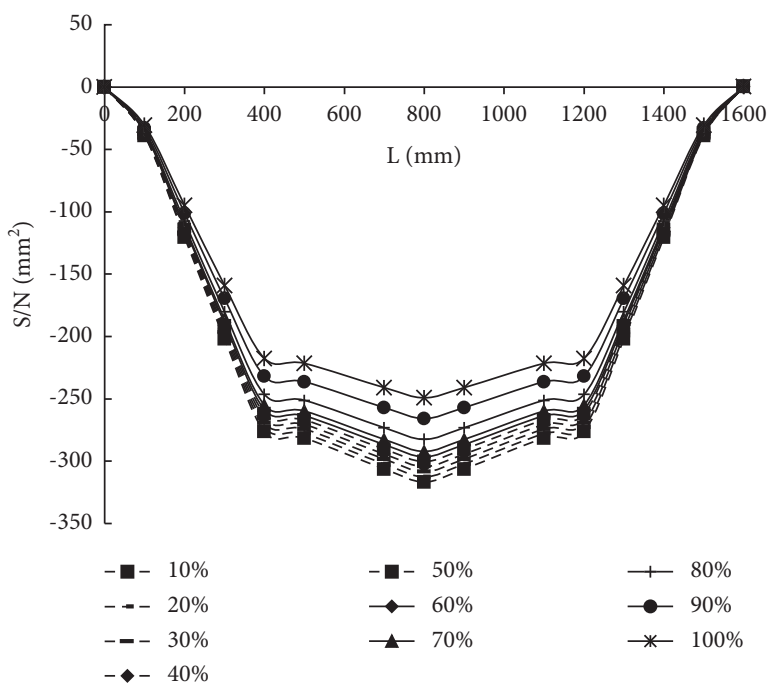

(c)

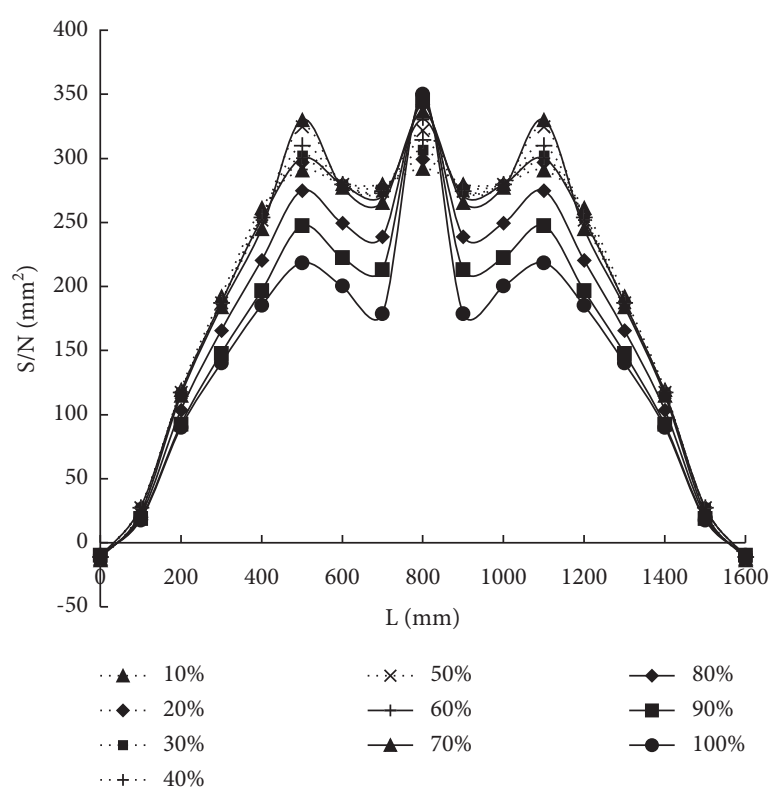

(b)

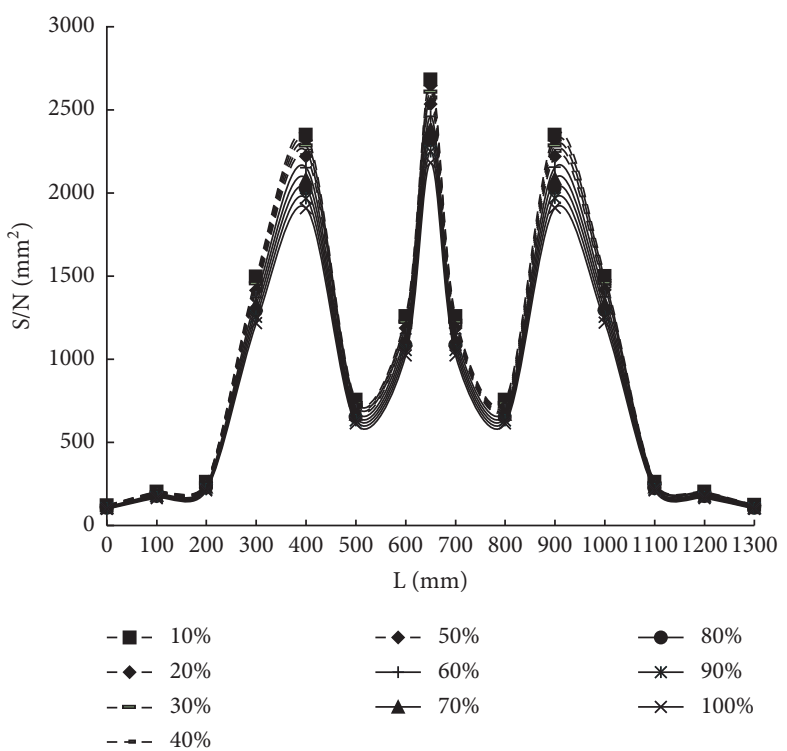

(d)

FiguRe 14: Effect of corrosion. (a) Load and deflection. (b) Stress along steel beam length. (c) Stress along steel beam width. (d) Stress along CFRP sheet's length.

loading point decreased quickly, but tensile stress in the midspan was almost the same as other damaged levels. The stress of CFRP sheet in the midspan was maximal and the stress decreased as the damaged level increased.

4.7.2. Flange Width of Steel Beam. Figure 15 shows the loaddeflection relationship of strengthened steel beam with different flange width. The stiffness of strengthened steel beam with $60 \mathrm{~mm}, 70 \mathrm{~mm}, 80 \mathrm{~mm}, 90 \mathrm{~mm}, 100 \mathrm{~mm}$, and $105 \mathrm{~mm}$ flange width was, respectively, $17.8 \%, 25.5 \%, 31.5 \%$, $35.5 \%, 40.1 \%$, and $41.8 \%$ greater than that of strengthened steel beam with $50 \mathrm{~mm}$ flange width. The ultimate load of strengthened steel beam with $60 \mathrm{~mm}, 70 \mathrm{~mm}, 80 \mathrm{~mm}$, $90 \mathrm{~mm}, 100 \mathrm{~mm}$, and $105 \mathrm{~mm}$ flange width was, respectively, $4 \%, 26 \%, 36.9 \%, 48.5 \%, 59.6 \%$, and $64.5 \%$ greater than that of strengthened steel beam with $50 \mathrm{~mm}$ flange width. When the flange width was $\leq 80 \mathrm{~mm}$, the load-deflection curves increased as linear elasticity after the steel beam yielded. When the flange width was $\geq 80 \mathrm{~mm}$, after steel beam yielded, as the deflection increased, the load would be unchanged. When the flange width was $\geq 105 \mathrm{~mm}$, the strengthened steel beam would be yielded as it failed. With the increase of flange width, the tensile stress of steel beam 


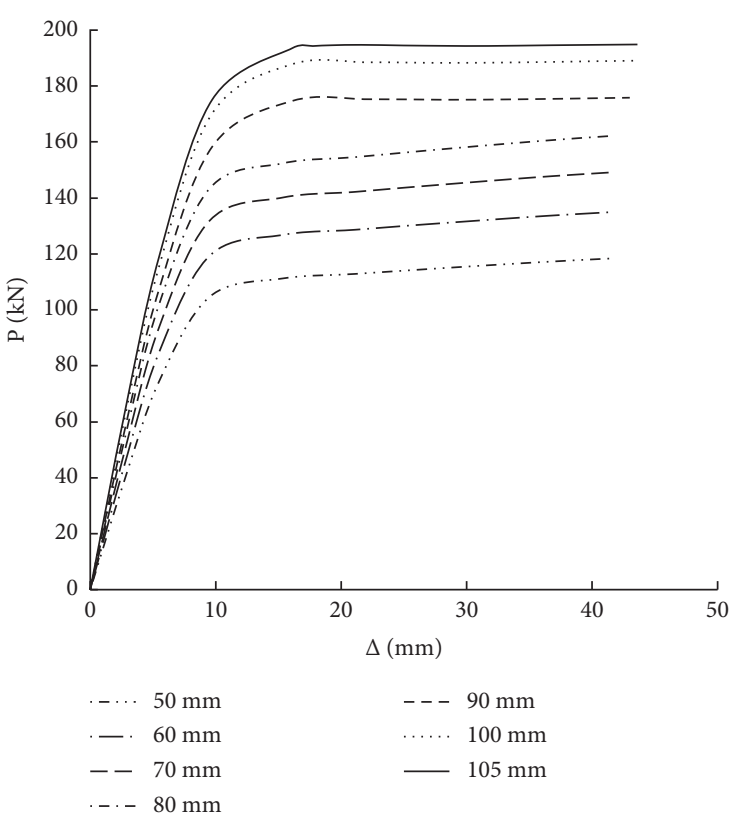

(a)

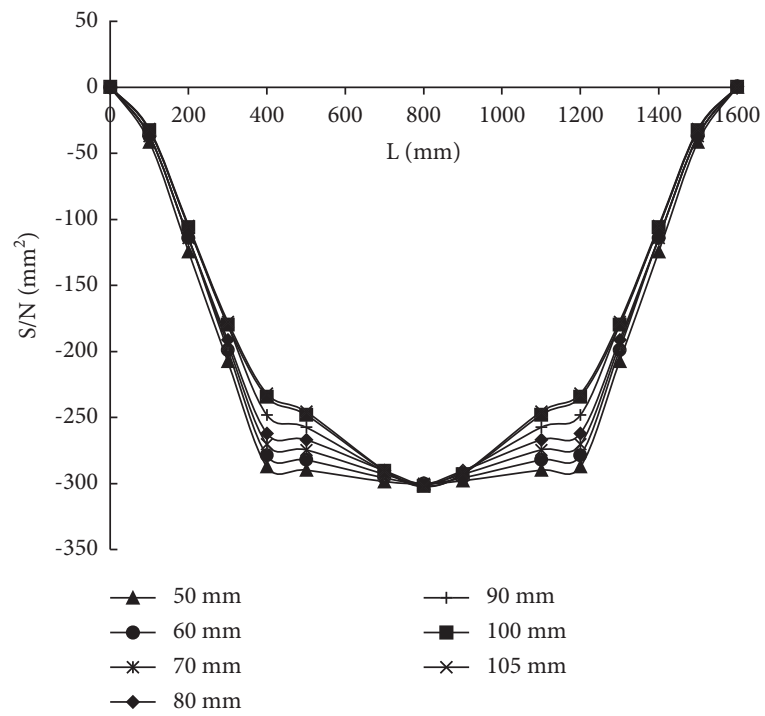

(c)

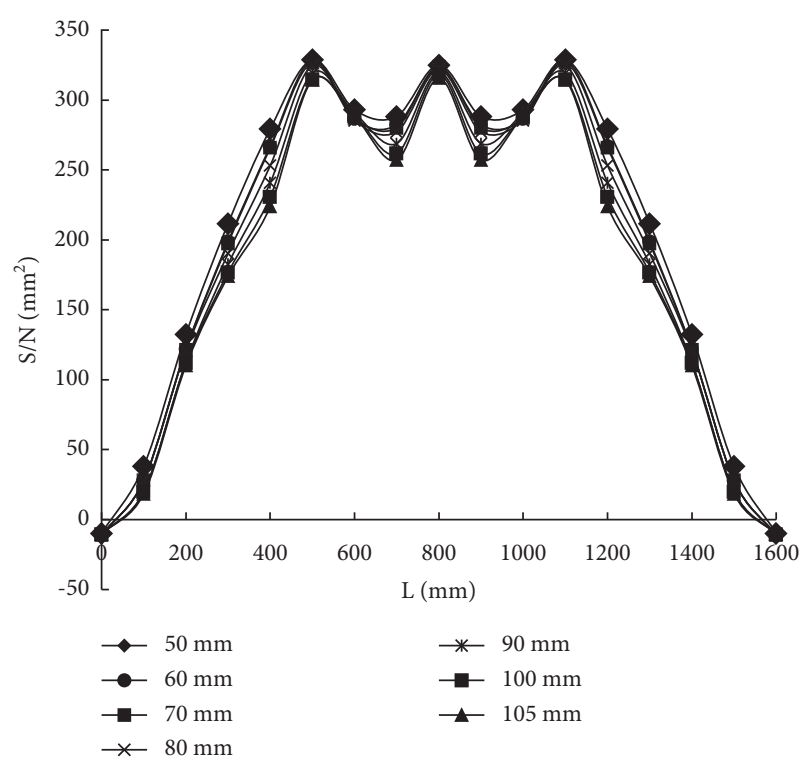

(b)

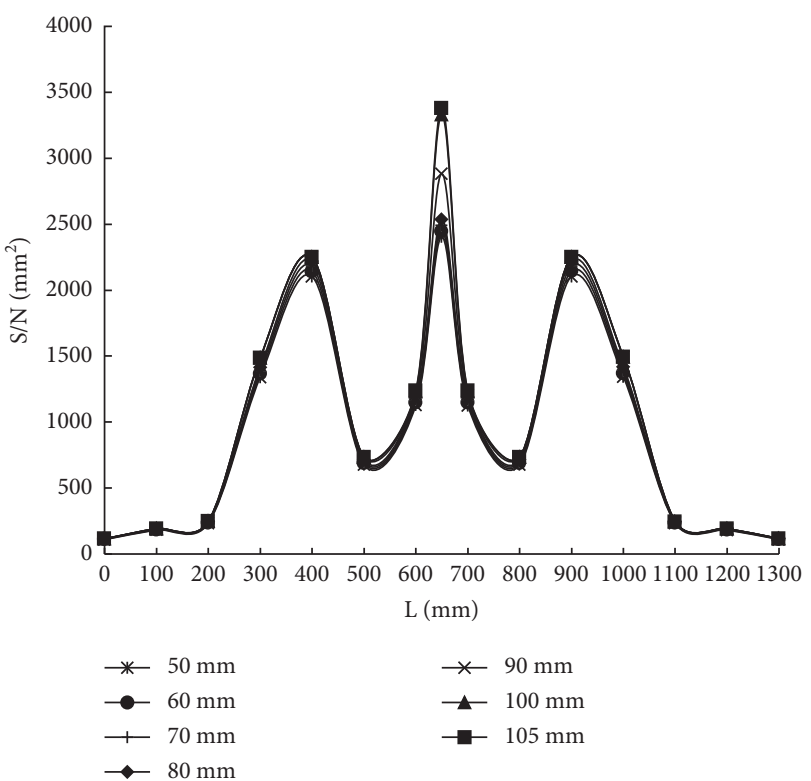

(d)

Figure 15: Effect of flange width. (a) Load and deflection. (b) Stress along steel beam length. (c) Stress along steel beam width. (d) Stress along CFRP sheet's length.

decreased gradually, but the decreasing amplitude was not large. The pressure stress at the loading point decreased gradually, but the pressure stress in the midspan was basically unchanged. When the flange width was larger than $80 \mathrm{~mm}$, the midspan stress of CFRP sheet increased greatly, but the stress at the loading point increased little. After the steel beam yielded, the load and deformation curves of the flange width greater than $80 \mathrm{~mm}$ were different from those of the flange width less than $80 \mathrm{~mm}$. This was because the utilization rate of CFRP sheet increased when the flange width was larger than $80 \mathrm{~mm}$.
4.7.3. Flange Thickness of Steel Beam. Figure 16 shows the load-deflection relationship of strengthened steel beam with different flange thickness. The stiffness of strengthened steel beam with $6 \mathrm{~mm}-14 \mathrm{~mm}$ flange thickness was, respectively, $15.2 \%, 21.4 \%, 26.7 \%, 31.1 \%, 34.9 \%, 38.4 \%, 41.1 \%, 43.5 \%$, and $45.9 \%$ greater than that of strengthened steel beam with $5 \mathrm{~mm}$ flange thickness. And the ultimate load of strengthened steel beam with $6 \mathrm{~mm}-14 \mathrm{~mm}$ flange thickness was, respectively, $9.7 \%, 18.4 \%, 26.9 \%, 35 \%, 43 \%, 51 \%, 58 \%$, $64.9 \%$, and $71.9 \%$ greater than that of strengthened steel beam with $5 \mathrm{~mm}$ flange thickness. The ultimate bearing 


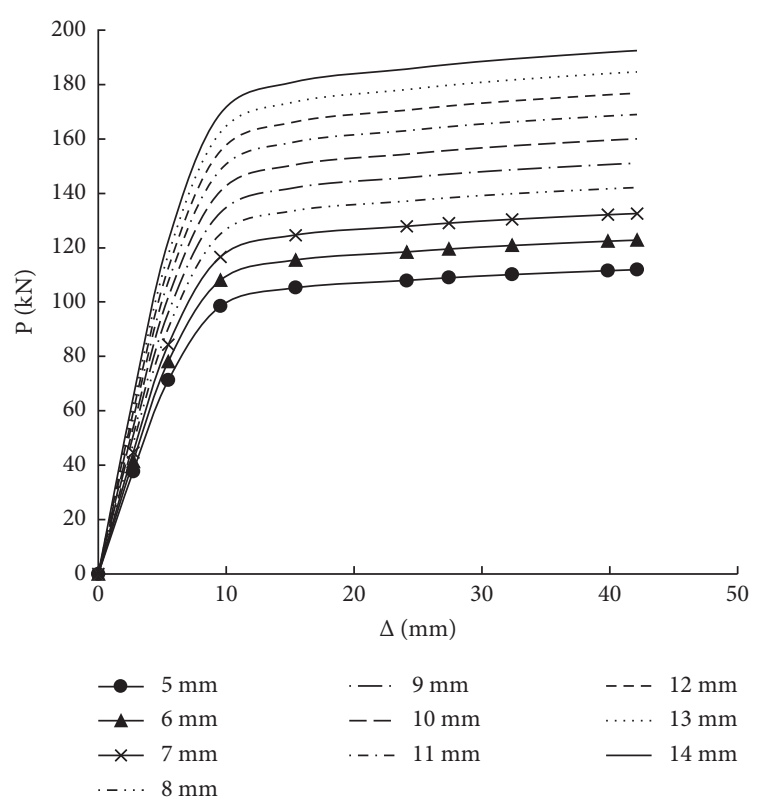

(a)

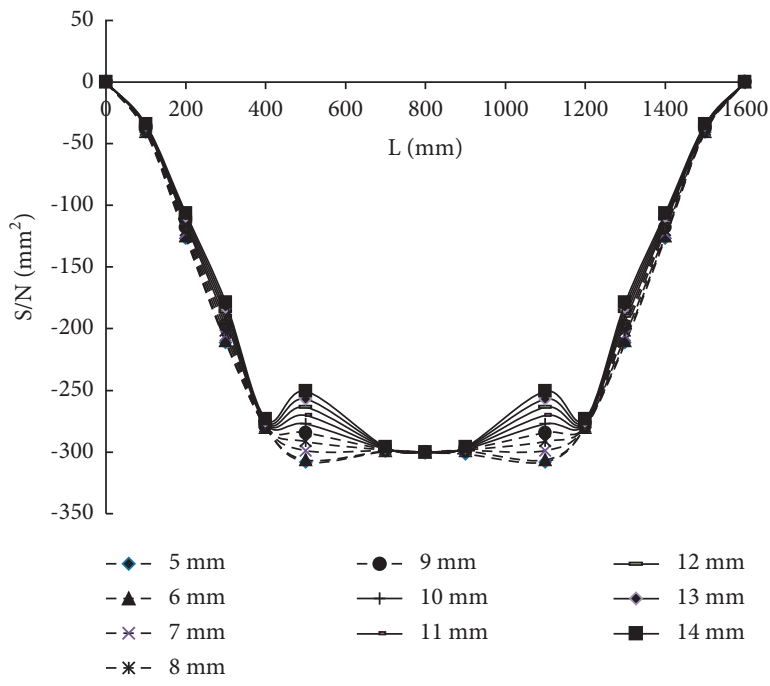

(c)

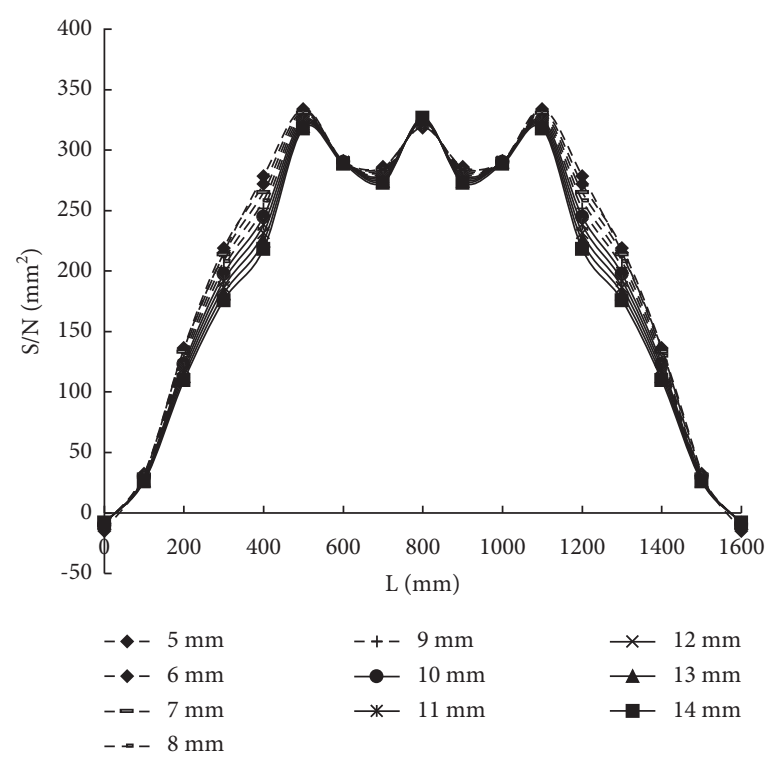

(b)

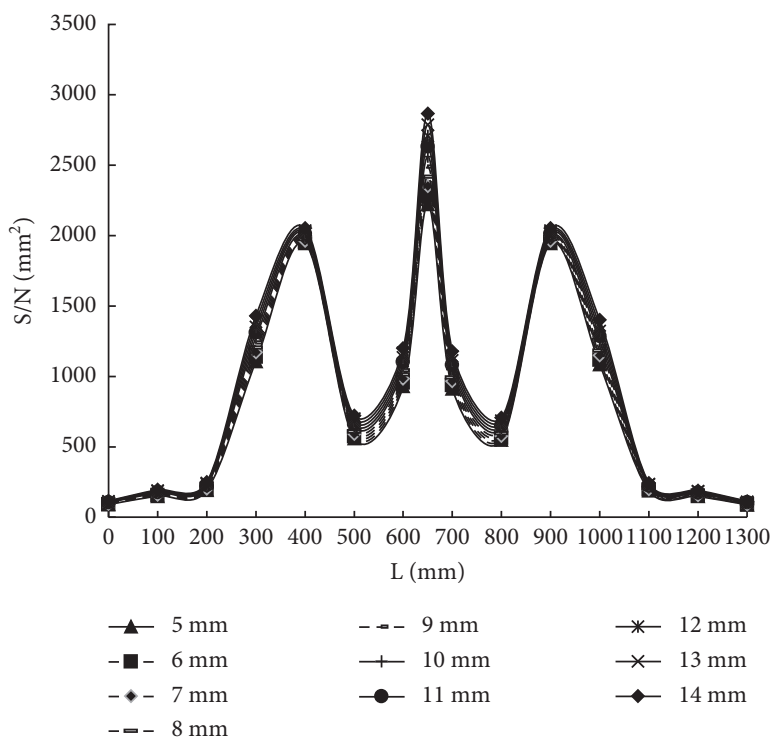

(d)

FiguRE 16: Effect of flange thickness. (a) Load and deflection. (b) Stress along steel beam length. (c) Stress along steel beam width. (d) Stress along CFRP sheet's length.

capacity would increase about $8 \%$ when the flange thickness increased per $1 \mathrm{~mm}$. With the increase of flange thickness, the tensile stress and pressure stress of loading point decreased gradually. The stress of CFRP sheet was the largest in the midspan, followed by the loading point. The larger the flange thickness was, the higher the utilization rate of CFRP sheet was.

4.7.4. Web Thickness of Steel Beam. Figure 17 shows the load-deflection relationship of strengthened steel beam with different web thickness. The stiffness of strengthened steel beam with $4 \mathrm{~mm}-12 \mathrm{~mm}$ web thickness was, respectively,
$12.7 \%, 17.2 \%, 21.9 \%, 24.8 \%, 28.1 \%, 31 \%, 33.9 \%, 35.9 \%$, and $38.3 \%$ greater than that of strengthened steel beam with $3 \mathrm{~mm}$ web thickness. And the ultimate load of strengthened steel beam with $4 \mathrm{~mm}-12 \mathrm{~mm}$ web thickness was, respectively, $7.5 \%, 12.4 \%, 19.3 \%, 23.8 \%, 29.5 \%, 35.2 \%, 40.8 \%$, $45.4 \%$, and $51.1 \%$ greater than that of strengthened steel beam with $3 \mathrm{~mm}$ web thickness. The ultimate bearing capacity would increase about $8 \%$ when the web thickness increased per $1 \mathrm{~mm}$. With the increase of web thickness, the midspan tensile stress of steel beam decreased gradually, and the tensile stress at loading point increased gradually. The pressure stress at loading point of steel beam increased with the increase of web thickness. The stress of CFRP sheet 


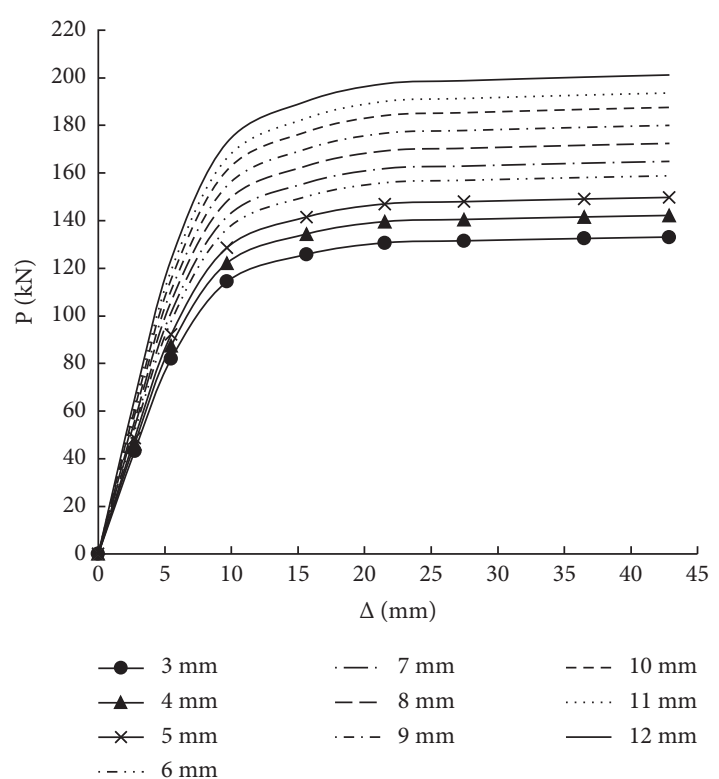

(a)

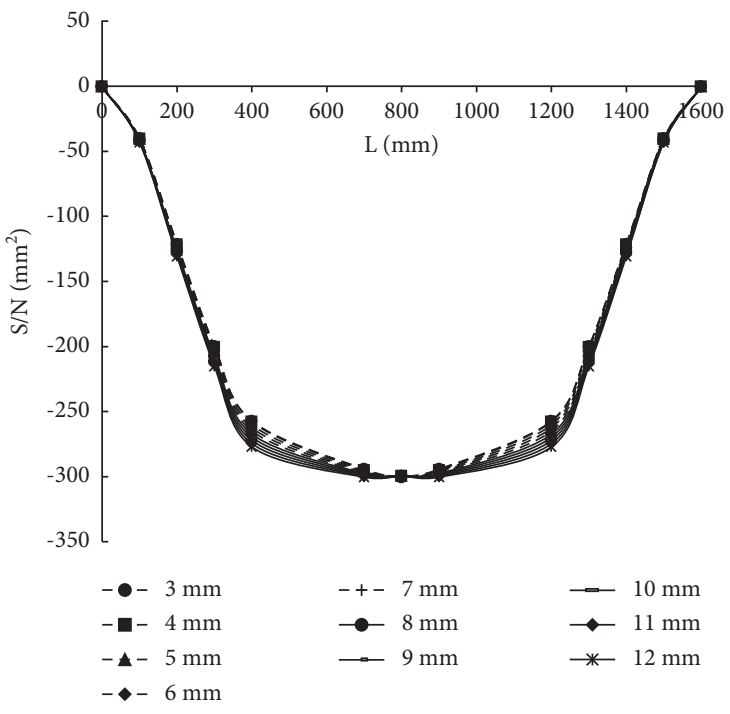

(c)

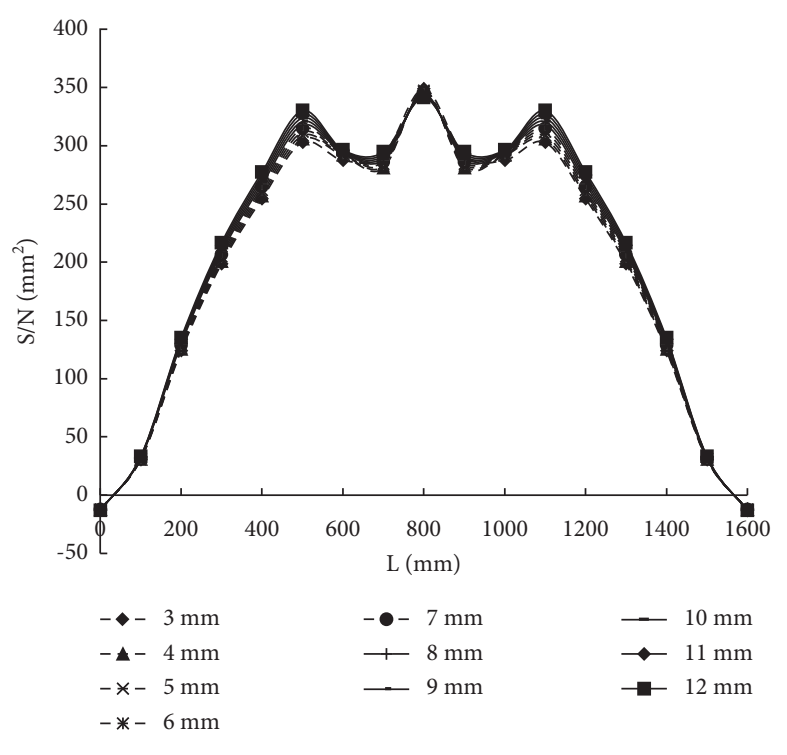

(b)

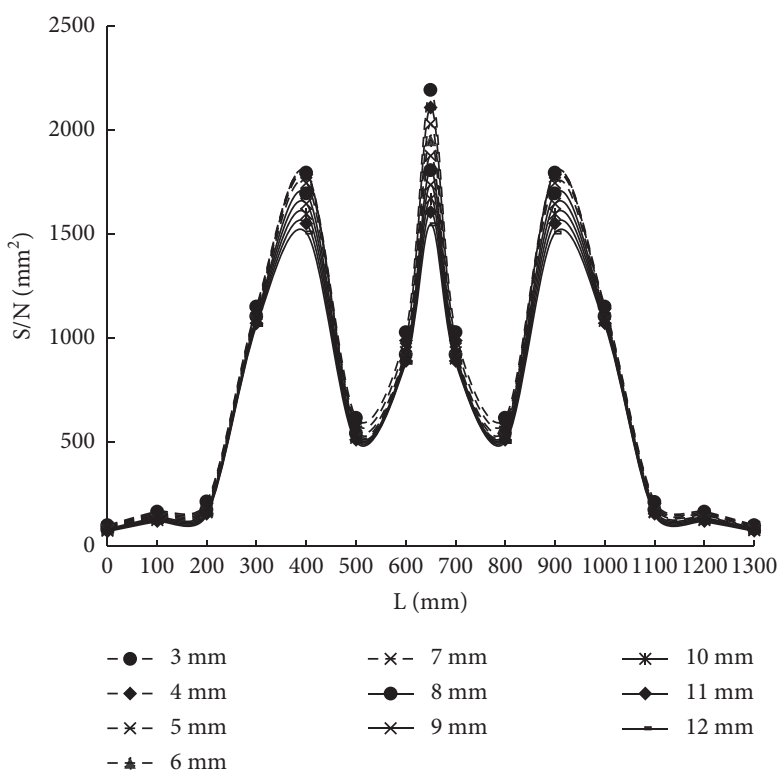

(d)

Figure 17: Effect of web thickness. (a) Load and deflection. (b) Stress along steel beam length. (c) Stress along steel beam width. (d) Stress along CFRP sheet's length.

decreased with the increase of web thickness, indicating that the increase of web thickness could reduce the utilization rate of CFRP sheet to a certain extent.

4.7.5. Thickness of CFRP Sheet. Figure 18 shows the loaddeflection relationship of strengthened steel beam with different CFRP sheet's thickness. The stiffness of strengthened steel beam with $0.15 \mathrm{~mm}-0.55 \mathrm{~mm}$ CFRP sheet's thickness was, respectively, 9.4\%, $11.6 \%, 14.2 \%, 15.8 \%$, $17.7 \%, 19.3 \%, 21.5 \%, 22.4 \%$, and $23.9 \%$ greater than that of strengthened steel beam with $0.1 \mathrm{~mm}$ CFRP sheet's thickness. And the ultimate load of strengthened steel beam with
$0.15 \mathrm{~mm}-0.55 \mathrm{~mm}$ CFRP sheet's thickness was, respectively, $3.1 \%, 5.6 \%, 8.3 \%, 10.9 \%, 13.3 \%, 15.7 \%, 18.1 \%, 20.3 \%$, and $22.5 \%$ greater than that of strengthened steel beam with $0.1 \mathrm{~mm}$ CFRP sheet's thickness. The ultimate bearing capacity would increase about $3 \%$ when the CFRP sheet's thickness increased per $0.05 \mathrm{~mm}$. The tensile stress and pressure stress of steel beam were both the largest in the midspan and at the loading point, and the change of tensile stress and pressure stress with the thickness of CFRP sheet was not obvious. The stress of CFRP sheet was the largest in the midspan, followed by the loading point. The utilization ratio of CFRP sheet decreased with the increase of the thickness of CFRP sheet. 


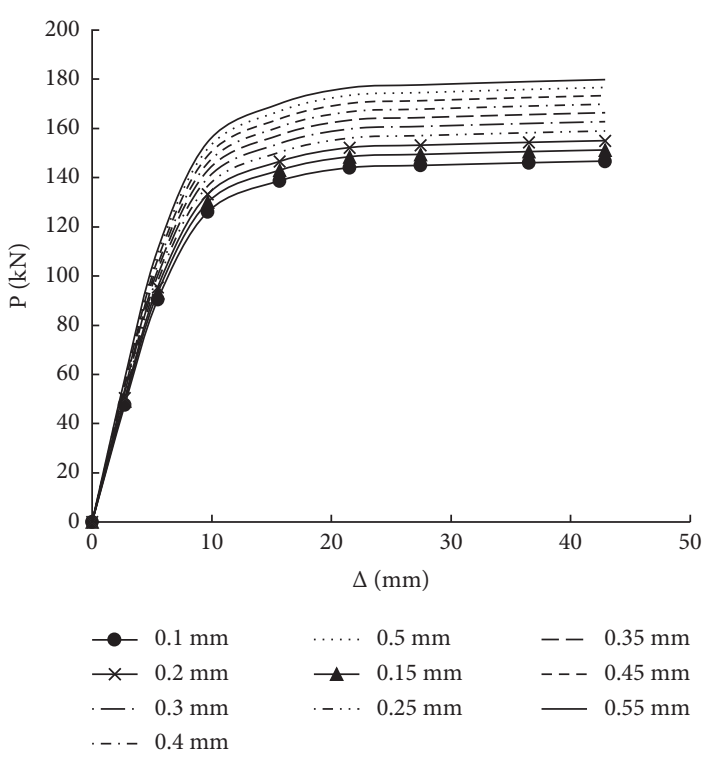

(a)

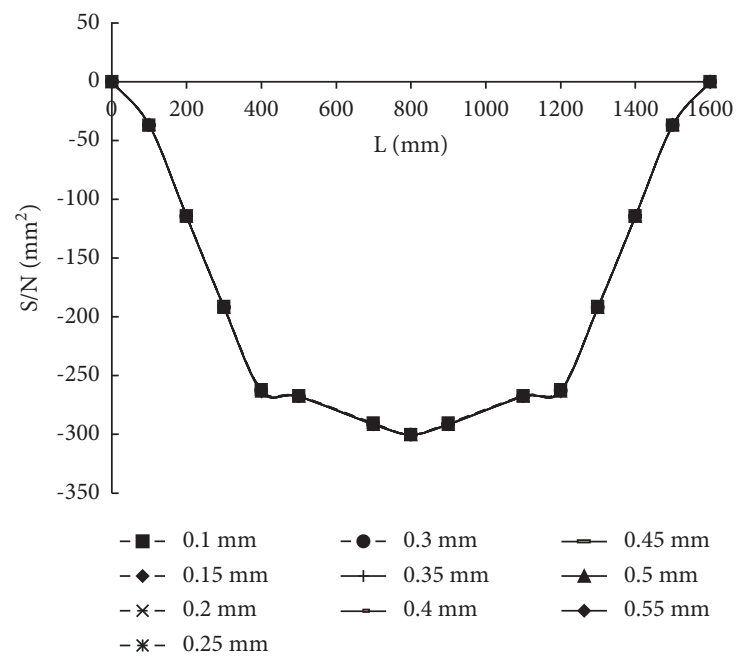

(c)

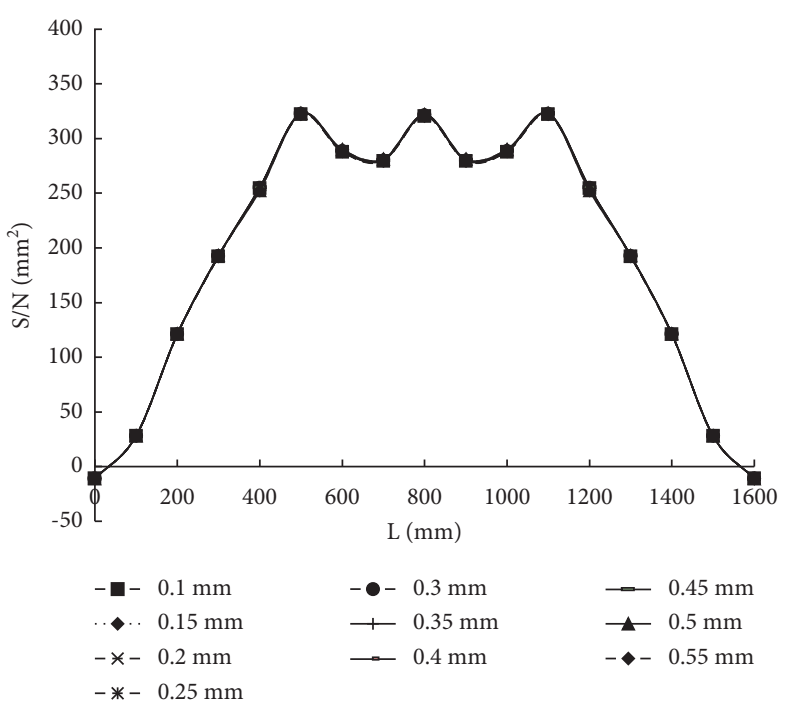

(b)

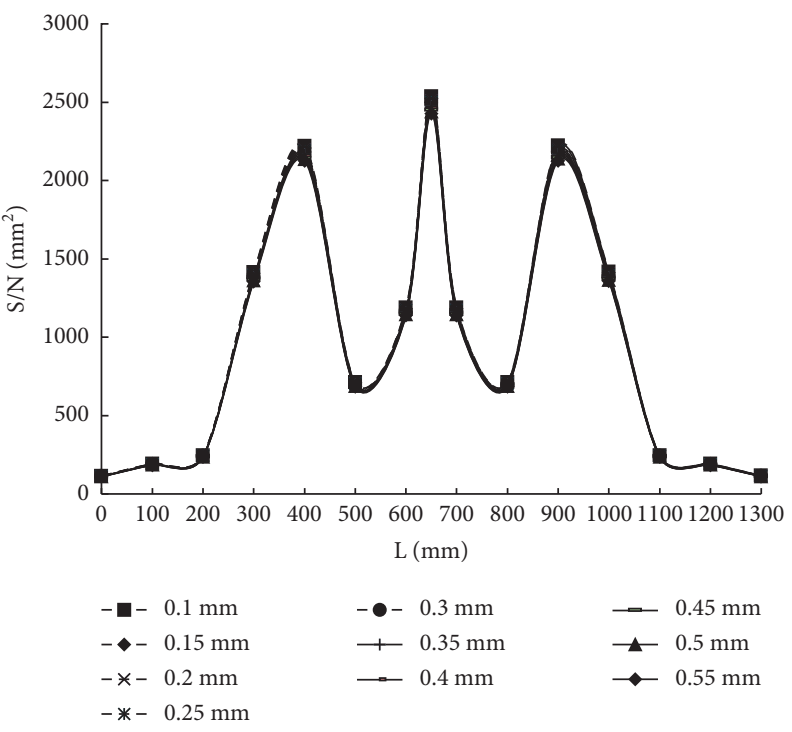

(d)

FIGURE 18: Effect of CFRP sheet's thickness. (a) Load and deflection. (b) Stress along steel beam length. (c) Stress along steel beam width. (d) Stress along CFRP sheet's length.

4.7.6. Width of CFRP Sheet. Figure 19 shows the load-deflection relationship of strengthened steel beam with different CFRP sheet's width. The stiffness of strengthened steel beam with $20 \mathrm{~mm}-70 \mathrm{~mm}$ CFRP sheet's width was, respectively, $8.5 \%, 10.4 \%, 11.8 \%, 12.6 \%, 14.7 \%$, and $15.8 \%$ greater than that of strengthened steel beam with $10 \mathrm{~mm}$ CFRP sheet's width. And the ultimate load of strengthened steel beam with $20 \mathrm{~mm}-70 \mathrm{~mm}$ CFRP sheet's width was, respectively, $1.9 \%, 4.2 \%, 5.8 \%, 6.6 \%, 9.4 \%$, and $10.9 \%$ greater than that of strengthened steel beam with $10 \mathrm{~mm}$ CFRP sheet's width. The ultimate bearing capacity would increase about 3\% when the CFRP sheet's width increased per $10 \mathrm{~mm}$. The change of the width of CFRP sheet had little effect on the tensile stress and pressure stress, but had an effect on the tensile stress near the loading point and the pressure stress near the midspan. The increase of the width of CFRP sheet had a great effect on the stress of CFRP sheet. Increasing the width of CFRP sheet can improve the utilization rate of CFRP sheet.

4.7.7. Prestressing Degree of CFRP Sheet. Figure 20 shows the load-deflection relationship of strengthened steel beam with different prestressed degree. The stiffness of strengthened steel beam with $7 \%, 13 \%, 20 \%$, and $30 \%$ prestressed degrees was, respectively, 3.5\%, 5.7\%, 7.5\%, and $11.5 \%$ greater than that of strengthened steel beam with 0 prestressed degree. And the ultimate load of strengthened steel beam with $7 \%, 13 \%, 20 \%$, and $30 \%$ prestressed degree was, respectively, 1.5\%, 3.6\%, 5.6\%, and 


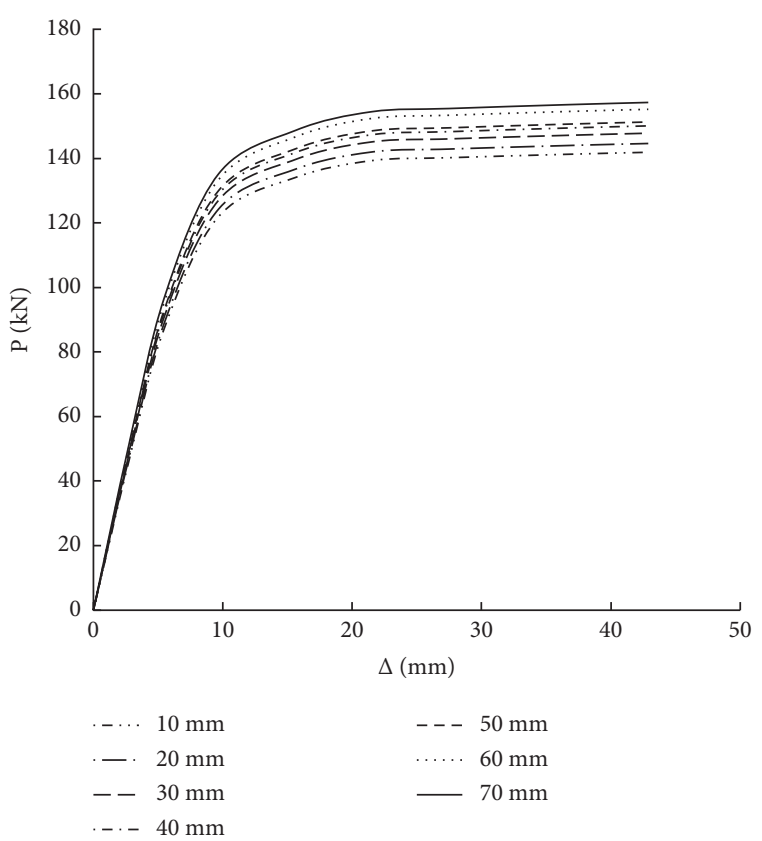

(a)

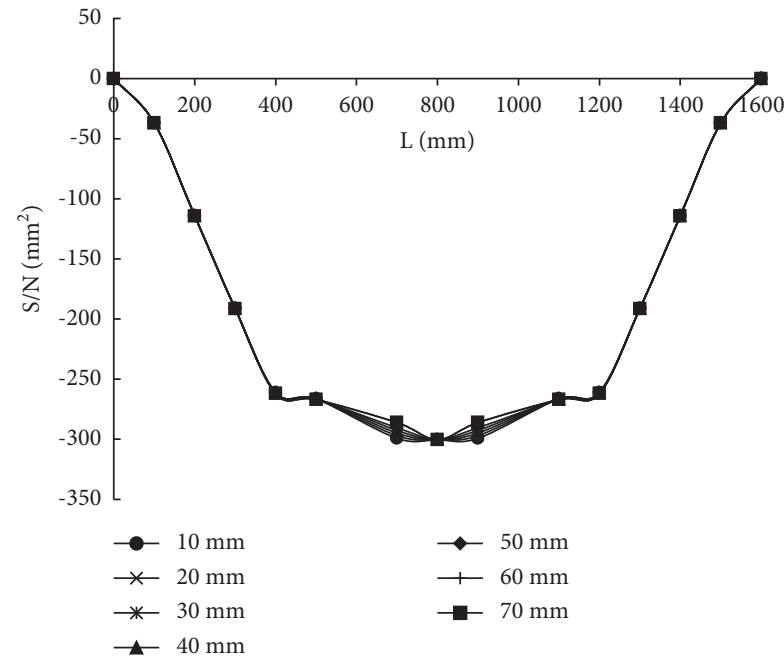

(c)

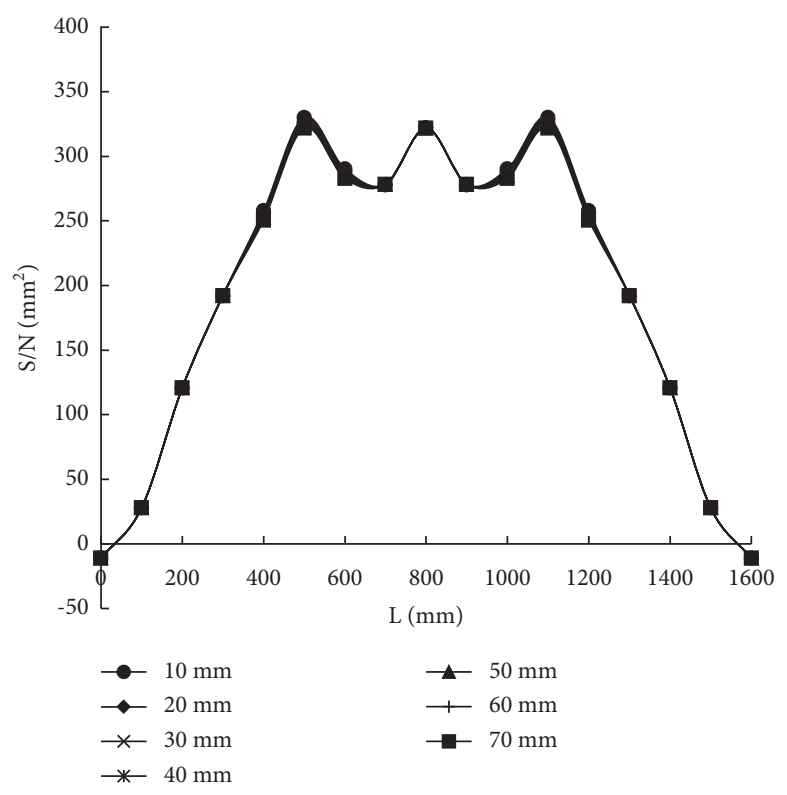

(b)

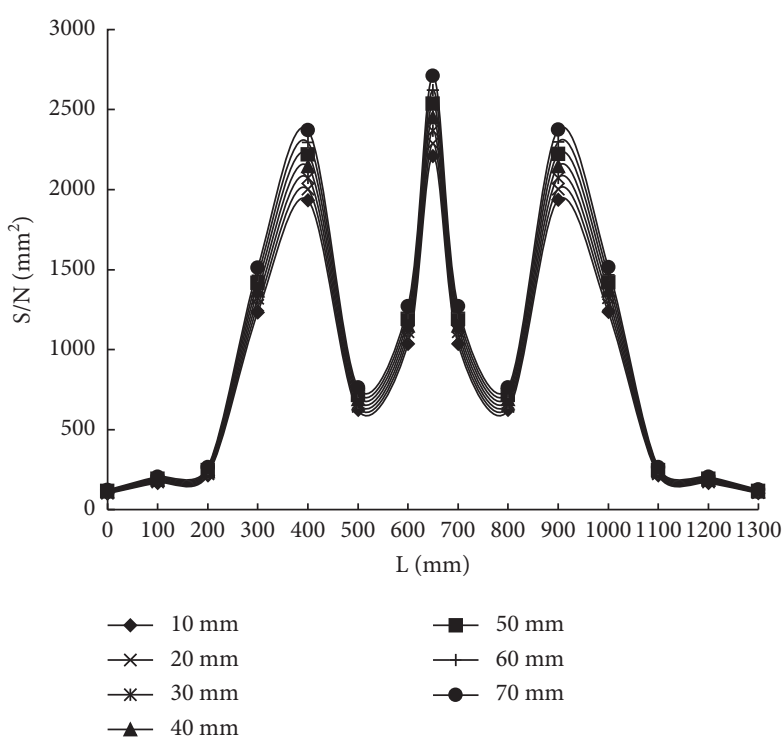

(d)

Figure 19: Effect of CFRP sheet's width. (a) Load and deflection. (b) Stress along steel beam length. (c) Stress along steel beam width. (d) Stress along CFRP sheet's length.

$8.3 \%$ greater than that of strengthened steel beam with 0 prestressed degree. The ultimate bearing capacity would increase about $1.5 \%$ when the prestressed degree increased about $7 \%$. The change of tensile stress of steel beam was the biggest in the midspan, and the pressure stress changed a little in the midspan and loading point, but the pressure stress changed slightly near the midspan. The stress of CFRP sheet increased with the increase of the prestressing degree. Prestressing degree increased about 7\%, and the stress of CFRP sheet would increase about 3\%, indicating that the increase of prestressing degree could significantly improve the utilization rate of CFRP sheet. 


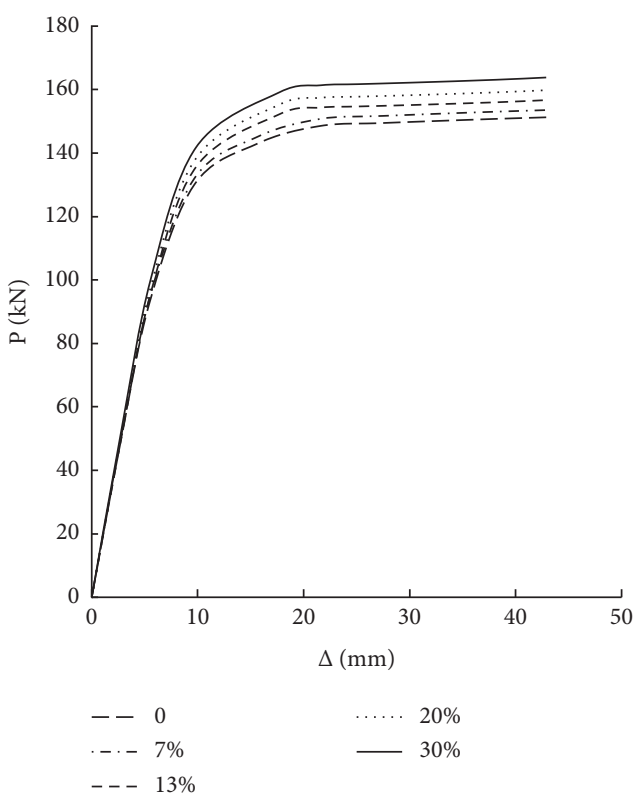

(a)

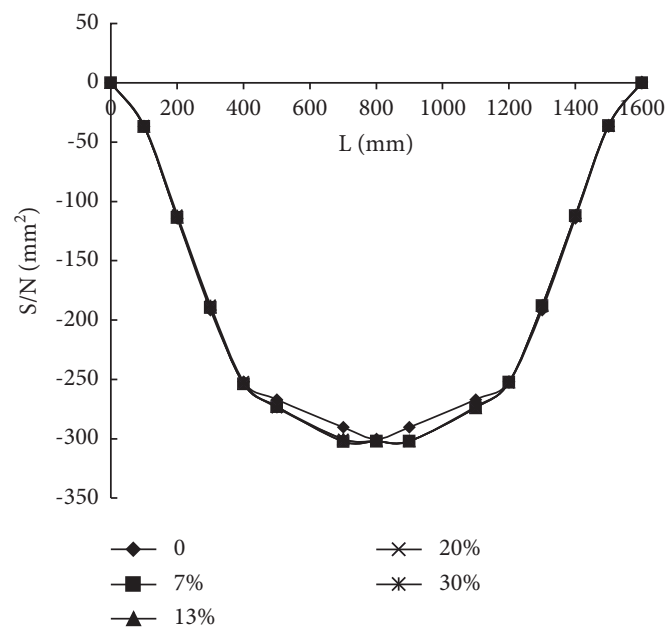

(c)

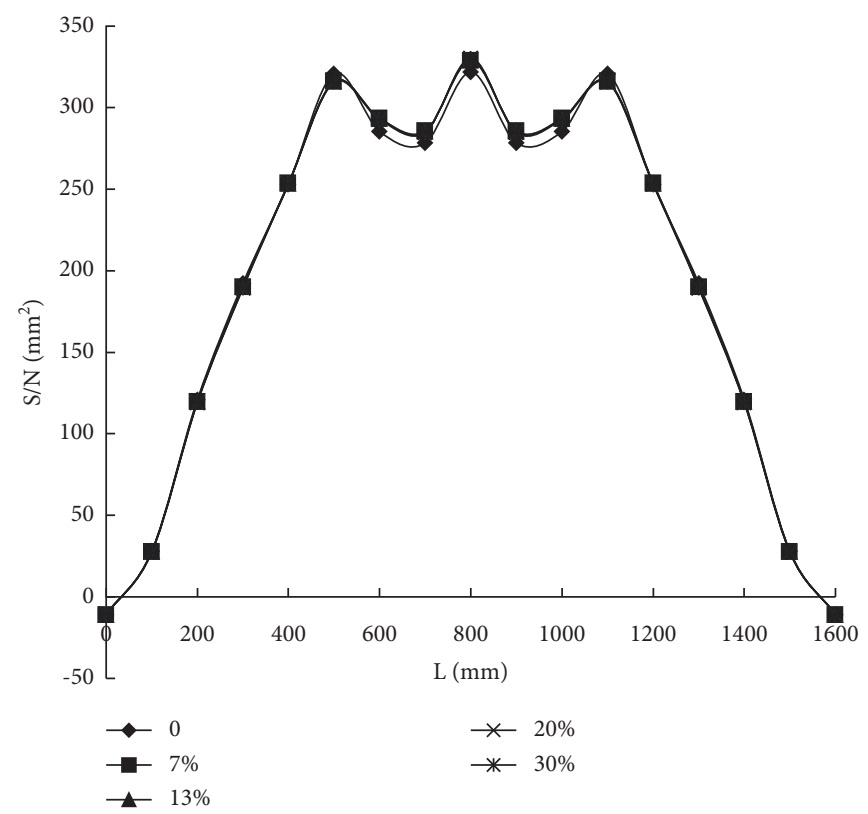

(b)

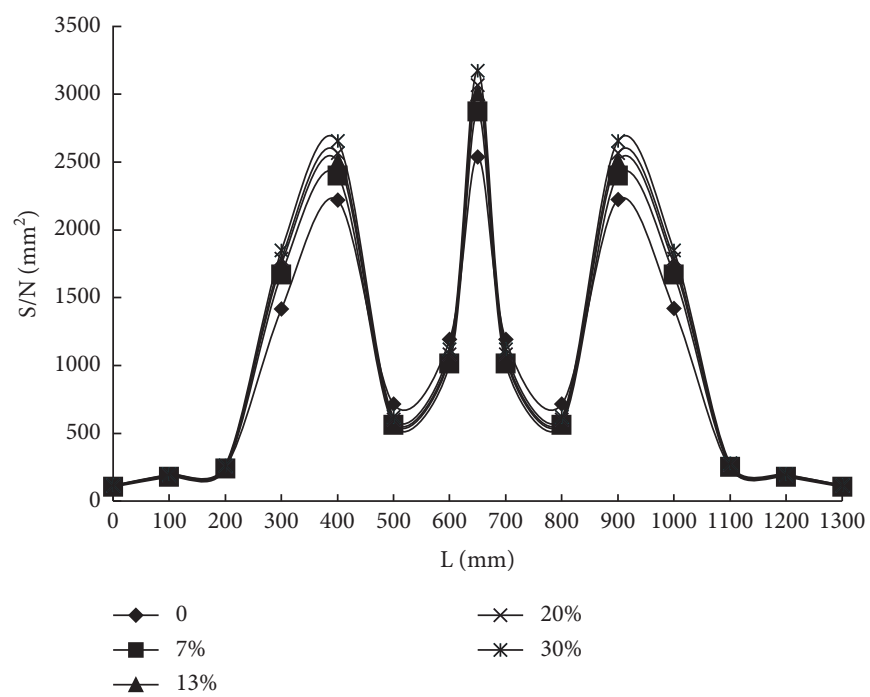

(d)

Figure 20: Effect of prestressing degree. (a) Load and deflection. (b) Stress along steel beam length. (c) Stress along steel beam width. (d) Stress along CFRP sheet's length.

\section{Conclusions}

(1) The test results showed that the steel beams repaired with prestressed CFRP sheet or CFRP sheet could display four distinct failure modes including the top flange buckling; some part of CFRP sheet debonding; CFRP sheet ruptured with the top flange buckling; CFRP sheet rupture. The damaged level had a significant effect on the stiffness, yield load, and ultimate load. And the prestressed CFRP sheet could increase the bearing capacity.

(2) By comparing the numerical results and test results, agreement was also achieved no matter the steel beams were bare, strengthened with CFRP sheet, or strengthened with prestressed CFRP sheet. The loaddeflection curve was nonlinear and it included three phases: elastic phase, elastic-plastic phase, and plastic phase.

(3) The numerical analysis results showed that the damaged level had a significant effect on the stiffness and ultimate bearing capacity. When the damaged level was $10 \%$, the bearing capacity after strengthening could exceed the steel beam without damage. When the flange width was $\geq 80 \mathrm{~mm}$, after the steel beam yielded, as the deflection increased, the bearing capacity would be unchanged. When the flange 
width was $\geq 105 \mathrm{~mm}$, the strengthened steel beam would be yielded as it failed. The bearing capacity would increase about $1.5 \%$ when the prestressing degree increased about $7 \%$ and the stress of CFRP sheet would increase about $3 \%$.

\section{Data Availability}

Some or all data, models, or code generated of used during the study are available from the corresponding author by request.

\section{Conflicts of Interest}

The authors declare that they have no conflicts of interest.

\section{Acknowledgments}

The authors wish to thank the Liaoning Provincial Department of Education Youth (No. LJ2020QNL006) and Open Fund Project of Key Laboratory of Ministry of Education for Disaster and Control of Major Engineering, Jinan University (20200904012).

\section{References}

[1] Z. Zhao, H. Liu, and B. Liang, "Bending capacity of corroded welded hollow spherical joints," Thin-Walled Structures, vol. 127, pp. 523-539, 2018.

[2] Z. Zhao, H. Zhang, L. Xian, and H. Liu, "Tensile strength of Q345 steel with random pitting corrosion based on numerical analysis," Thin-Walled Structures, vol. 148, Article ID 106579, 2020.

[3] Y. J. Kim and K. A. Harries, "Fatigue behavior of damaged steel beams repaired with CFRP strips," Engineering Structures, vol. 33, no. 5, pp. 1491-1502, 2011.

[4] G. Wu, H.-T. Wang, Z.-S. Wu, H.-Y. Liu, Y. Ren, and Yi Ren, "Experimental study on the fatigue behavior of steel beams strengthened with different fiber-reinforced composite plates," Journal of Composites for Construction, vol. 16, no. 2, pp. 127-137, 2012.

[5] Q. Q. Yu, T. Chen, X. L. Gu, X. L. Zhao, and Z. G. Xiao, "Fatigue behavior of CFRP strengthened steel plates with different degrees of damage," Thin-Walled Structures, vol. 69, pp. 10-17, 2013.

[6] M. Bocciarelli and P. Colombi, "On the elasto-plastic behavior of continuous steel beams reinforced by bonded CFRP lamina," Engineering Structures, vol. 49, pp. 756-766, 2013.

[7] A. Hmidan, Y. J. Kim, and S. Yazdani, "Correction factors for stress intensity of CFRP-strengthened wide-flange steel beams with various crack configurations," Construction and Building Materials, vol. 70, pp. 522-530, 2014.

[8] P. Colombi, G. Fava, C. Poggi, and L. Sonzogni, "Fatigue reinforcement of steel elements by CFRP materials: experimental evidence, analytical model and numerical simulation," Procedia Engineering, vol. 74, pp. 384-387, 2014.

[9] E. Ghafoori and M. Motavalli, "Lateral-torsional buckling of steel I-beams retrofitted by bonded and un-bonded CFRP laminates with different pre-stress levels: experimental and numerical study," Construction and Building Materials, vol. 76, pp. 194-206, 2015.

[10] L. Wang, W. Hou, H. Han, and J. Huo, "Repair of flange damage steel-concrete composite girders using CFRP sheets,"
Structural Engineering and Mechanics, vol. 55, no. 3, pp. 511-523, 2015.

[11] P. Colombi and G. Fava, "Experimental study on the fatigue behaviour of cracked steel beams repaired with CFRP plates," Engineering Fracture Mechanics, vol. 145, pp. 128-142, 2015.

[12] M. Gholami, A. R. M. Sam, A. K. Marsono, M. M. Tahir, and I. Faridmehr, "Performance of steel beams strengthened with pultruded CFRP plate under various exposures," Steel and Composite Structures, vol. 20, no. 5, pp. 999-1022, 2016.

[13] N. J. Aljabar, X. L. Zhao, R. Al-Mahaidi, E. Ghafoori, M. Motavalli, and N. Powers, "Effect of crack orientation on fatigue behavior of CFRP-strengthened steel plates," Composite Structures, vol. 152, pp. 295-305, 2016.

[14] L. Hu, P. Feng, and X.-L. Zhao, "Fatigue design of CFRP strengthened steel members," Thin-Walled Structures, vol. 119, pp. 482-498, 2017.

[15] O. Yousefi, K. Narmashiri, and M. Reza Ghaemdoust, "Structural behaviors of notched steel beams strengthened using CFRP strips," Steel and Composite Structures, vol. 25, no. 1 , pp. $35-43,2017$.

[16] I. Jankowiak and A. Madaj, "Numerical analysis of effectiveness of strengthening concrete slab in tension of the steelconcrete composite beam using pretensioned CFRP strips," Civil and Environmental Engineering Reports, vol. 27, no. 4, pp. 005-015, 2017.

[17] H. E. Omar, S. S. Sherif, and A. M. Sherif, "Flexural strength of steel I-beams reinforced with CFRP sheets at tension flange," Journal of Constructional Steel Research, vol. 148, pp. 572-588, 2018.

[18] M. Bocciarelli, P. Colombi, T. D’Antino, and G. Fava, "Intermediate crack induced debonding in steel beams reinforced with CFRP plates under fatigue loading," Engineering Structures, vol. 171, pp. 883-893, 2018.

[19] E. Martinelli, A. Hosseini, E. Ghafoori, and M. Motavalli, "Behavior of prestressed CFRP plates bonded to steel substrate: numerical modeling and experimental validation," Composite Structures, vol. 207, pp. 974-984, 2019.

[20] J. Li, J. Deng, Y. Wang, J. Guan, and H. Zheng, "Experimental study of notched steel beams strengthened with a CFRP plate subjected to overloading fatigue and wetting/drying cycles," Composite Structures, vol. 209, pp. 634-643, 2019. 